\title{
Col·leccionisme i gust artístic de Josep Anton de Cabanyes i Ballester (I797- I 852 ) a través del manuscrit Catálogo y descripción de algunos cuadros que posee Dn. José Antonio de Cabanyes (c. I 850 )
}

Francesc Miralpeix Vilamala

Universitat de Girona. Institut de Recerca Històrica (IRH)

francesc.miralpeix@udg.edu

RESUM

L'article presenta el manuscrit inèdit del catàleg de la pinacoteca del comerciant Josep Anton de Cabanyes (I797-I852), expert viatger per l'Europa postnapoleònica. S'hi analitza el personatge i la seva afició per les col-leccions, alhora que s'hi ressegueix la fortuna de la seva collecció, una bona part de la qual es conserva a la Masia d'en Cabanyes de Vilanova i la Geltrú (Barcelona).

Paraules clau:

col-leccionisme; segle XIX; Catalunya, pintura flamenca i holandesa; escola bolonyesa i romana; Carracci; Correggio; Sarto; Albani; Domenichino; Bayeu; Salvatore Rosa; Viladomat

\section{AbStRACT}

The collection and artistic taste of Joseph Anton de Cabanyes Ballester (1797-1852): The manuscript Catálogo y descripción de algunos cuadros que posee Dn. José Antonio de Cabanyes [c. 1850] and the compilation of preserved works

The article presents the unpublished manuscript of the catalog of the gallery belonging to the merchant Josep Anton de Cabanyes (I 797 - I 8 52), an avid traveler to postNapoleonic Europe. We analyze the collector's character and passion for art, as well as the destiny of his collection, largely preserved in the Masia d'en Cabanyes manor of Vilanova i la Geltrú in Barcelona.

\section{Keywords:}

collecting; nineteenth century; Catalonia; Dutch and Flemish painting; Roman and Bolognese School; Carracci; Correggio; Sarto; Albani; Domenichino; Bayeu; Salvatore Rosa; Viladomat 
Couvrir un corps, opâque et uni d'an peu de couleur sans relief, et, par ce moyen si simple, y faire voir tous les objets qu'on veut, ainsi que tout ce qui les environne, dans les éloignemens qu'exigent leurs distances respectives, avec la même vérité et la même illusion qu'on les voit dans un miroir fidelle, annonce un art si magique, étonne si fort l'esprit humain, fait une impression si agréable, produit un attrait si séduisant, qu'il devient absolument impossible, que le nom- bre de ceux qui aiment les tableaux puisse jamais diminuer ${ }^{1}$.

(F. X. de BURTIN ( 1808 ), Traité historique et pratique des connaissances qui sont nécessaires à tout amateur de tableaux..., 2, p. 75 )

$\mathrm{E}$ 1 i 849, la Guia General de Barcelona, de Manuel Saurí i José Matas, consignava l'existència, a la ciutat comtal, del Museu de Ciències Naturals dels botànics Salvador, del gabinet de naturalia del Dr. Soler i de la col-lecció d'armes i objectes arqueològics de Juan Cortada, al carrer de la Mercè. De les dues darreres, en deia que o bé era recent (la del Dr. Cortada) o bé tenia pocs objectes (la del Dr. Soler). S'hi ressenyaven dues pinacoteques: la de l'Escola de Nobles Arts instal-lada a l'edifici de Llotja, ben assortida amb les obres procedents dels convents suprimits, i la galeria de pintures del mestre i antiquari Esteve Paluzie Cantalozella, amb predominança d'obres d'escola valenciana. S'hi anotava, també, l'existència d'alguns monetaris particulars, com els de José Carreras o el de D. N. Casanyas².

El testimoni de la Guia General de Saurí i Matas és revelador de la situació en què es trobava el col-leccionisme privat a Barcelona $-\mathrm{i}$, per extensió, arreu del Principat-, pràcticament inexistent per aquelles dates. Deixant de banda les colleccions de la petita i mitjana noblesa catalana $i$ les que es formaren en els entorns eclesiàstics, com la dels canonges tarragonins Ramon Foguet i Carlos Benito González de Posada, la del pare Francisco Izquierdo, la del Dr. Iglesias, la del canonge Jaume Ripoll, la del premonstratenc Jaume Pasqual o la del músic moianès Josep Elias ${ }^{3}$, la major part de les quals no sobrevisqueren a la Guerra del Francès, la generalització del fenomen del col-leccionisme a Catalunya no s'instaurà amb força fins a la segona meitat del segle XIX. Abans calgué una presa de consciència sobre el valor del patrimoni artístic i monumental i una educació de les elits burgeses, que, a poc a poc, s'empeltaren del cos teòric que els acadèmics de
Belles Arts i de Bones Lletres anaven atorgant a la conservació, restauració i coneixement del patrimoni del país. Les grans exposicions d'arts sumptuàries i la consolidació dels museus hi feren la resta, però ja ben entrat el darrer terç de segle XIX. A partir d'aquest moment, les colleccions de Bosch i Pazzi, Coroleu, Carreras d'Argerich, Campaner, Estruch, Sala, Faraudo, etc. emplenaran les pàgines de les guies i dels catàlegs en allò que Vicente Maestre, amb encert, ha adjectivat com «la puesta de largo del coleccionismo barcelonés» ${ }^{4}$.

Entre la formació de la barcelonina Escola Gratuïta de Disseny, el I775, i fins la definitiva implantació de l'Acadèmia Provincial de Belles Arts de Barcelona, el I850, que, com hem dit, contribuí a fer de mirall a l'incipient colleccionisme burgès del Principat, hi ha ben pocs casos de col-leccions constituïdes amb una concepció clarament moderna, en què els criteris de gust i de selecció personals s'imposin a la tradició dels gabinets acumulatius de meravelles o als monetaris numismàtics $\mathrm{i}$ arqueològics. I moltes menys, per no dir que no n'hi ha pràcticament cap, que continguin peces del mercat internacional de primer nivell. A tot plegat, cal afegir-hi, encara, un fet insòlit: que aquestes obres vagin acompanyades d'un minuciós catàleg descriptiu, fet amb bons coneixements dels corrents artístics de l'art europeu dels segles XVI al XVIII. Aquest és el cas del vilanoví Josep Anton de Cabanyes i Ballester (Vilanova i la Geltrú, I797-I852), l'afició colleccionista del qual ha passat pràcticament desapercebuda en les grans monografies del gènere (figura I) $)^{5}$. Aquest article vol apropar el personatge al lloc que li pertoca com a precursor del col-leccionisme artístic a la Catalunya decimonònica $i$, alhora, donar a conèixer el manuscrit on descriu, amb una gran sensibilitat estètica $\mathrm{i}$ 
literària - segurament també un fet pràcticament insòlit $-{ }^{6}$, vuitanta-dues pintures de la seva propietat, intitulat Catálogo y descripción de algunos cuadros que posee Dn. José Antonio de Cabanyes (apèndix documental I $)^{7}$. No pot ser objecte d'aquest estudi, per raons òbvies d'espai, l'anàlisi minuciosa de totes $\mathrm{i}$ cadascuna de les obres que es conserven i que creiem que tenen correlació amb les entrades del manuscrit, sinó fer un primer esbós del personatge i del document, fins ara mai publicat de forma íntegra ${ }^{8}$.

\section{Josep Anton de Cabanyes. Colleccionisme burgès avant la lettre}

Deu anys després d'abandonar definitivament Brussel-les, on havia passat els millors anys de la seva vida (una constatació reiterada en els nombrosos escrits que deixà), Josep Anton de Cabanyes, ric comerciant vilanoví, escriptor i colleccionista, melòman, traductor i pintor ocasional, germà del poeta romàntic Manuel de $\mathrm{Ca}$ banyes, es lamentava, des de la finca de Bellver, a tocar de Vilobí del Penedès, de l'infortuni del seu retorn:

[...] ¡Ay dia desastroso! / ¡Momento el más fatal de mi existencia! ¿Cómo tan gran quebranto, / Cómo tanta inclemencia, / No lo hizo el postrimero de mi vida? / Desde entonces el llanto / Y en tétrico fastidio consumido. / Bélgica, tierra que cual patria quiero, / Pues más que ha do nací mi amor mereces. / En tu seno acogido, yo mil veces / El resto trascordé del mundo entero?.

Vivia el retorn amb tanta amargor, que el versà $a m b$ un dolor profund, de tarannà romàntic: «[...] De en medio tanto bien arrebatado / Mi dicha es cambiada en amargura. / Mi corazón sangrando, aimé y doliente / El recuerdo grabado aún conserva / De aquella hora fatal de pena acerba / Tan vivo cual si fuera la presente» ${ }^{10}$. No en va, Josep Anton de Cabanyes considerava la ciutat belga com «[... el centro de la civilización de Europa y cuando la degé estaba aquella ciudad en el más alto punto de su brillantez» ${ }^{11}$. A Brussel-les, hi veia una llum, la del nord, que l'escalfava i, en canvi, trobava gèlida la càlida claror mediterrània del Garraf: «En I834 me hallo en Bellver, solo y algo mohíno; la atmósfera política la ve todo el mundo, y la que cubre este rincón en este momento es nublosa, y el aire húmedo y frio» ${ }^{12}$.

Efectivament, corrien temps convulsos. Un any abans de la seva arribada, el I833, havia esclatat la primera carlinada, que duraria fins al

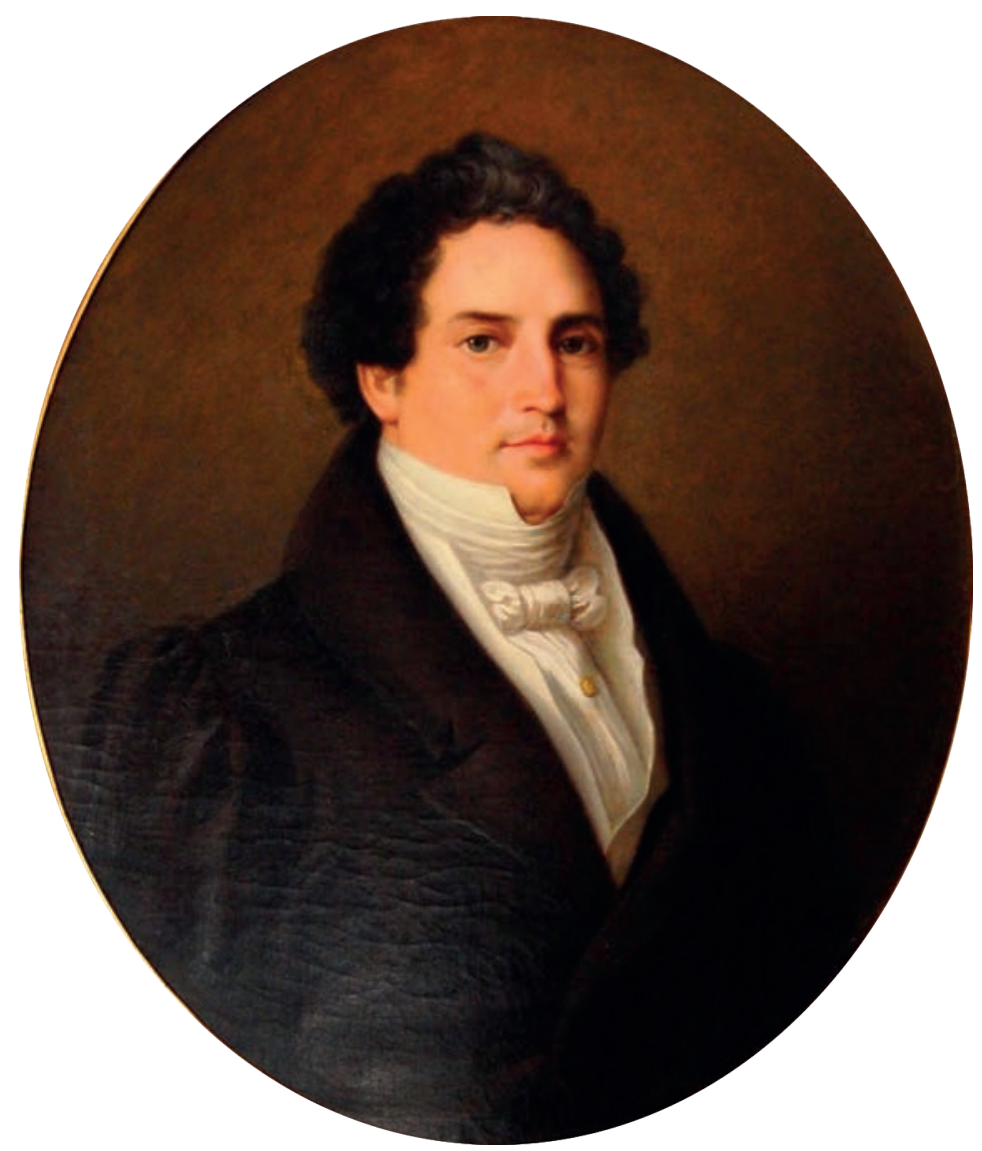

Figura 1.

Pelegrí Clavé, Retrat de Josep Anton de Cabanyes, Masia d'en Cabanyes. Fotografia: Masia d'en Cabanyes. Arxiu fotogràfic del Centre d'Interpretació del Romanticisme Manuel de Cabanyes. Autors: Diego Calderon i Carles Andreu.

I 840, i els bàndols carlista i isabelí estaven en plena disputa per la successió al tron espanyol, amb el rerefons de les revoltes anticlericals que, a l'estiu del trenta-quatre, afectaren Madrid de ple i que, poc després, esclatarien en forma de bullangues a Barcelona. No hi ha dubte que el nostre protagonista, que s'havia format sota l'auspici del seu pare Llorenç de Cabanyes Fuster $\mathrm{i}$ del seu oncle Josep Maria de Cabanyes, patia per la hisenda $i$ els negocis i segurament per la seva pròpia integritat física i la de la seva família, atès que la seva formació afrancesada i el seu posicionament obertament liberal -així queda reflectit en la seva àmplia biblioteca $\mathrm{i}$ en els comentaris dels seus escrits - el deixaven exposat a aquells que el veien com un adinerat terratinent. Des de Bellver mateix, i entre les notes de les obres literàries que traduïa per matar el tedi, Cabanyes escrivia:

Cuando leo a Plutarco veo lo que es la Madre Patria, y lo que son los patriotas: cuando leo nuestras Gacetas y me acuerdo de lo que yo mismo he visto, sólo percibo a una Madrastra, y unos Tartufos políticos. Quien me trata 
como un hijo, aquel es mi padre: quien me arruina, me inquieta, me castiga, me atormenta, me persigue, me amenaza, me asesina, es mi contrario, mi mortal enemigo ${ }^{13}$.

Aquesta mateixa preocupació l'expressà el I 836, quan uns carlins s'atansaren a la Masia d'en Cabanyes i se n'emportaren el mosso Sebastià Puig i el seu fill ${ }^{14}$.

La sensació de trobar-se en un país roí, sempre en contrast, és clar, amb la bellesa dels indrets i l'afabilitat de les gents de Bèlgica, es manifestà de manera molt punyent i sovintejada en contra de la ciutat de Barcelona. Cabanyes, que era un home culte i refinat que parlava amb fluïdesa català, castellà, holandès, francès, italià, anglès i alemany, amant de les arts i de les lletres, trobava que Barcelona era una ciutat provinciana i pretensiosa. El maig de i 837, a punt d'embarcar cap a un exili que el portaria a una llarga estada de dos anys a Mallorca, Josep Anton dedicà un sonet a la ciutat, que deia que l'havia trobat - metafòricament, és clar-, a «la parte escusada» del vaixell de vapor: «[...] O símil disparate impertinente / que, más claro el sol del mediodía, salta a los ojos de cualquier persona: / pues mucho más estolida es la gente / que ha dado en la ridícula manía / de querer llamar culta a Barcelona» ${ }^{15}$. En les notes d'un altre poema, també s'hi referia de forma semblant $\mathrm{i}$ hi apuntava uns interessantíssims comentaris sobre el canvi de gust de les classes benestants, que veien vetustos els temes religiosos dels quadres que durant tants anys havien adornat les estances dels seus avantpassats:

(i4) La única y pobrísima colección de la Lonja dice ella sola cuanto se puede decir sobre el particular. En la sala de paisaje no hay ni un solo original, ni una buena copia. Colección particular no hay ninguna. Hace poco que se vendieron siete grandes cuadros de Viladomat (distinguido pintor catalán) por veinticuatro duros, y eso a sabiendas de toda esta cultísima ciudad. En muchas casas hay buenos cuadros, que los tienen arrinconados al desván, o porque dicen que son negros y entristecen los cuartos, o porque eran de los abuelos, y por consiguiente de moda antigua, o en fin porque siendo la mayor parte de asunto religioso los miran por esto mismo como impropios de adornar las estancias de gente culta e ilustrada. (I5) En todo el orbe no hay ciudad más desdichada que esta en cuanto a monumentos públicos modernamente construidos. Todas las fuentes sin exceptuar ni una, la fachada que se da de la Casa de la Ciudad, y que afeará todavía más aquella plazuela, la puerta del Jardín del General, el observatorio con que han desfigurado la Lonja, la Casa de Xifré seis pies más larga que la Lonja, etc. etc. etc. son pruebas palpables ${ }^{16}$.

Malgrat tot, Josep Anton visqué llargues temporades a Barcelona, on la família tenia casa al carrer de Mercaders.

\section{Conformació i gust artístic}

Entre els llibres de la biblioteca de Josep Anton de Cabanyes, a banda dels nombrosíssims de poesia i literatura que posseïa i que ja donen una idea de la seva altíssima competència intel-lectual ${ }^{17}$, hi havia una edició de 1770 de les Réflexions critiques sur la poésie et sur la peinture, del teòric Jean-Baptiste Dubos, una obra que clamava per la capacitat que tenien les arts de commoure els esperits. Tenia, també, una primera edició de 1757 dels Nouveaux principes de la perspective linéaire, avec un essai sur le mélange des couleurs par Newton ${ }^{18} \mathrm{i}$ un bon nombre de catàlegs de museus $i$ galeries de diferents països ${ }^{19}$. No en va, Josep Anton, a banda de formar-se a Amsterdam en una companyia exportadora quan tenia 20 anys - seguint la formació del seu avi Llorenç de Cabanyes i Boet, que ho havia fet a la casa Hope de la ciutat holandesa $^{20}-\mathrm{i}$ de viatjar a Holanda i Bèlgica entre I 822 i I 824, estigué també a Anglaterra, França, Suïssa i Itàlia. Barcelona, en vista de la seva formació i de l'experiència que havia adquirit, devia quedar a anys llum de la seva avidesa cultural. En aquest sentit, el comentari que dedica als pintors de l'Escola de Nobles Arts de la Junta de Comerç de Barcelona, que obviaren unes obres del pintor català Antoni Viladomat que ell mateix acabaria comprant, és demolidor: «Los pintores de Lonja los conocían, y los ilustres Señores de aquella Junta titulada Protectora de las Bellas Artes no hallaron a bien emplear 24 duros para aumentar su miserable Museo. Tal es la Ciudad que con ridículo empeño denominan culta! ${ }^{21}$. En termes semblants s'expressà en diferents moments sobre una Barcelona que trobava, a banda d'insegura, com també la hi veié l'escriptora George Sand al seu pas per la Ciutat Comtal, que coincidí a l'illa de Mallorca quan hi era Josep Anton, molt inculta: «La juventud de esta ciudad se distingue en general no tanto por su profunda ignorancia, como por los modales más groseros [...] Es difícil hallar de venta en ninguna de estas Librerías una obra que sea de interés. Por poco distinguida que sea ni el Librero conoce el título, y al instante responde que sería necesario acudir a Madrid por ella» ${ }^{22}$.

El bagatge cultural que Josep Anton de Cabanyes aconseguí de la seva exquisida formació i del seu contacte amb les elits d'una societat refinadíssima com era la dels Països Baixos d'aquells anys 
posteriors a les guerres napoleòniques el marcaren de per vida, fins al punt d'emular, en la mesura de les seves possibilitats, el comportament que creia que li corresponia per la seva condició de ric hisendat. No començà de zero, però. El seu pare, Llorenç de Cabanyes i Fuster (1758-I8I4), casat amb una de les pubilles més ben situades de Vilanova, ric comerciant de vins i aiguardents, va fer arreglar les cases que el seu sogre, Josep Fuster, tenia al centre de la vila, a la plaça de les Cols, fent xamfrà amb el carrer del Comerç, on actualment hi ha un conegut restaurant. Igual com trobem a moltes de les cases nobles de Barcelona, de Reus, de Terrassa, de la Selva del Camp i de tantes altres ciutats puixants de la fi del segle XVIII, les famílies benestants de la burgesia catalana ampliaren i feren construir espaioses residències revestides de fastuoses decoracions pintades a les diferents estances, en la línia de les decoracions de la vilanovina casa Papiol. A la casa Cabanyes de Vilanova, Llorenç hi feu representar un ric programa iconogràfic $i$ ornamental de matriu neoclàssica, amb temes mitològics i bíblics realitzats pel pintor Tomàs Solanes (i per Pau Rigalt?), en aquells anys, un dels artistes barcelonins més reputats (figura 2) ${ }^{23}$. Paral-lelament, i seguint el comportament de les elits barcelonines de la fi del segle XVIII que adquirien propietats a la banda alta de la ciutat per tal d'emprar-les com a residències de descans, a la manera de les vil-les suburbanes renaixentistes, Llorenç de Cabanyes adquirí, el I 790 , la finca Can Parellada al marquès de Llupià. En aquest indret, s'hi erigí la Masia d'en Cabanyes, un dels edificis més singulars de l'arquitectura neoclàssica catalana, el disseny del qual anà a càrrec, segons deducció d'Oriol Pi de Cabanyes, de l'enginyer italià Domenico Bagutti, que també traçà els jardins neoclàssics del laberint d'Horta per a Joan Antoni Desvalls i d'Ardena, marquès de Llupià i d'Alfarràs (figura 3). Si la quinta ubicada a quatre vents és d'un interès especial, a banda de la pròpia arquitectura neopal-ladiana de la casa, també ho és una bellíssima maqueta de fusta de la masia - que podria donar suport a la hipòtesi que darrere hi havia un arquitecte italià - $\mathrm{i}$ una pintura anònima de principis del segle XIX que reprodueix la masia en una vista (figura 4$)^{24}$. Aquesta casa, avui reconvertida en la coneguda Masia d'en Cabanyes - declarada, l’any 20I4, Bé Cultural d'Interès Nacional (BCIN) en la categoria de monument històric-, serà el destí final de la collecció de pintures.

Llorenç de Cabanyes i Fuster morí el i8I4, i la seva segona esposa, Caterina Ballester de Carro, es posà al capdavant de l'administració de les finques i dels negocis durant un llarg període de temps, el suficient perquè el primogènit Josep Anton s'acabés de formar a Amsterdam. Com hem explicat en començar, el i 824 , Josep

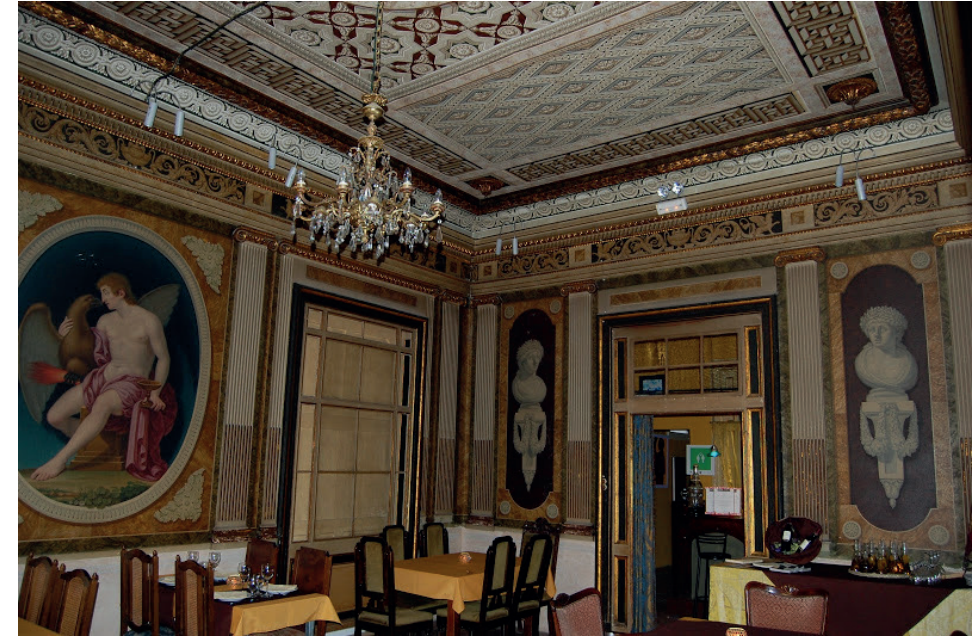

Figura 2.

Interior de la casa Cabanyes de la plaça de les cols de Vilanova i la Geltrú, decorada amb pintures de Tomàs Solanes (i Pau Rigalt?). Fotografia: Patrimoni de Vilanova i la Geltrú.

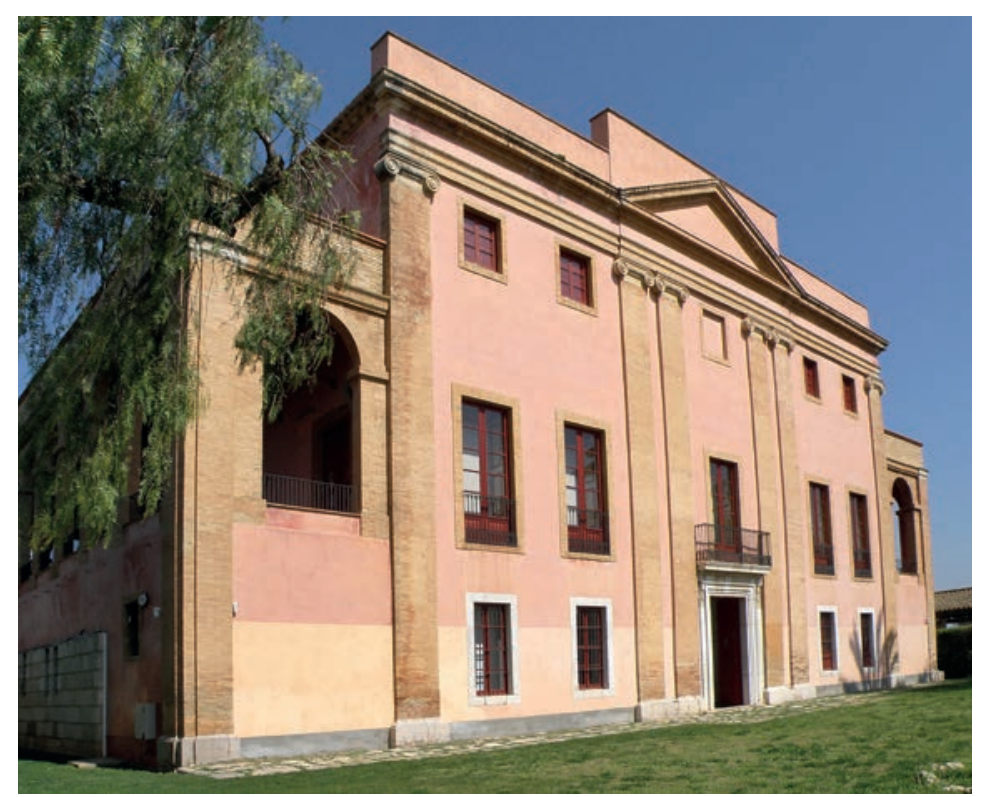

Figura 3.

Masia d'en Cabanyes. Exterior. Fotografia: Wikimedia Commons.

Anton retornà obeint la voluntat de la seva mare i, potser, obligat per les noves circumstàncies polítiques sorgides de la restauració borbònica. A partir d'aquell moment, es va fer càrrec dels negocis de la societat Cabanyes \& Fuster, sense deixar en cap moment de cultivar el seu gust per les arts i la literatura.

\section{De la «mania» de col-leccionar a la necessitat de catalogar}

No és difícil suposar que l'afició del nostre personatge per les arts i per les lletres se li devia empeltar als Països Baixos i en els múlti- 


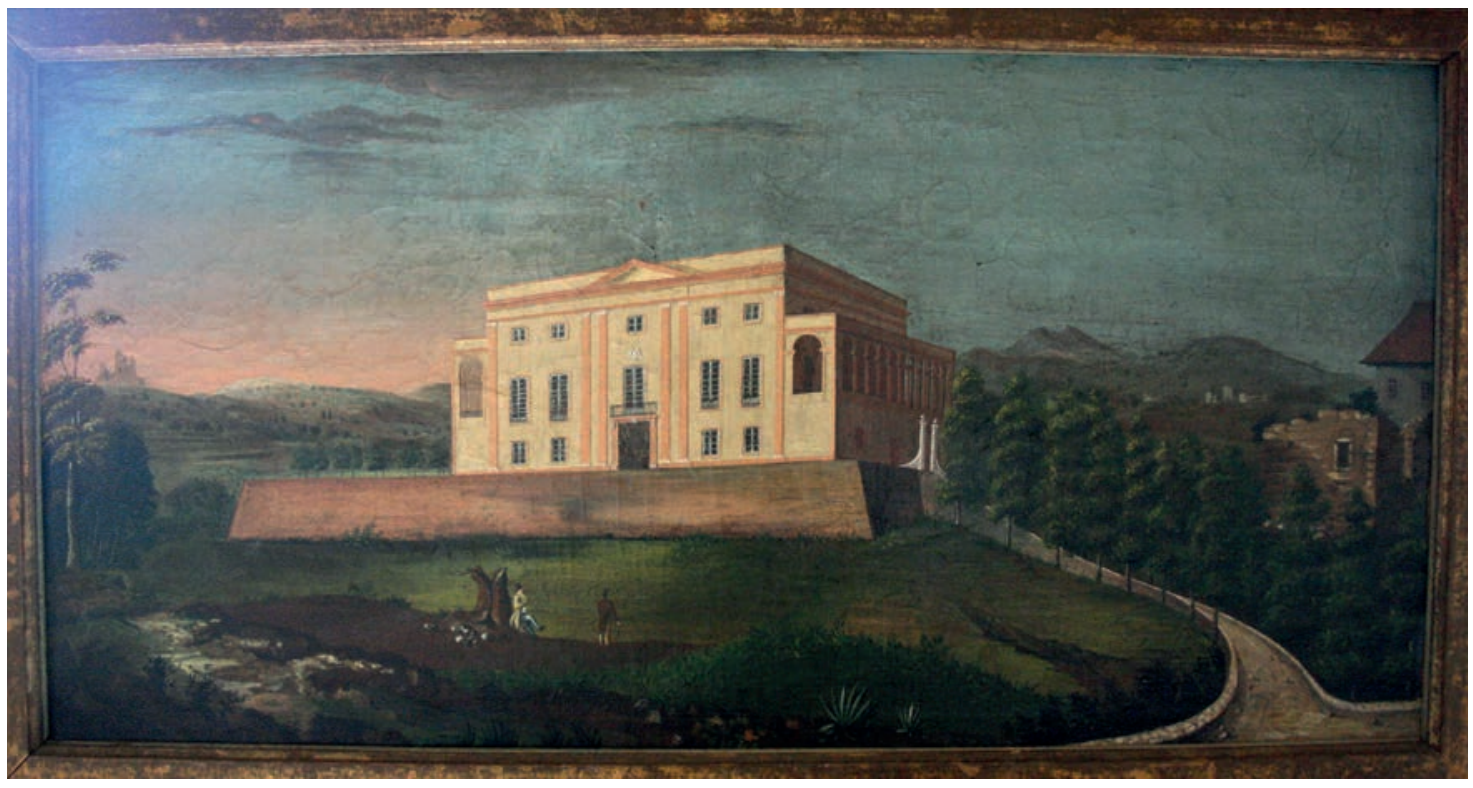

Figura 4.

ANÒnIM, Vista de la masia d'en Cabanyes (segle XIX). Fotografia: Arxiu fotogràfic del Centre d'Interpretació del Romanticisme Manuel de Cabanyes. Autors: Diego Calderon i Carles Andreu.

ples viatges que feu per Europa. Estava avesat a emprar les guies dels grans museus i de les grans col-leccions que, a principis del segle XIX, començaven a ser molt habituals i que els viatgers del Grand Tour adquirien per a la seva biblioteca, en bona part gràcies al creixent interès que, des de mitjan segle XVIII, sentien per la història de l'art i pel patrimoni antic i modern. Ell mateix, però, s'adonà que una col-lecció despertava més interès com més i millor es coneixia la història i les vicissituds de les obres que la integraven. Sense anar més lluny, quan visità les col-leccions del cardenal Antoni Despuig i Dameto, servades al Predi de Raixa, al palau dels comtes de Montenegro, es lamentà de la mala catalogació de les peces, que conduïen - deiaa confusions, agreujades pel capellà custodi de la col-lecció, que en deia «algun disparate» ${ }^{25}$.

No deuria ser, però, l'única motivació que l'empenyé a catalogar la seva pinacoteca. En realitat, Josep Anton de Cabanyes atresorava una inclinació per la història que practicà escrivint una documentada crònica sobre els orígens dels Cabanyes, ni tampoc li eren llunyanes la crítica d'art i l'estètica, que ell mateix cultivà fixant el record de les impressions que li causaven les obres i els espais que visitava. Són extraordinàries, en aquest sentit, les anotacions de les obres d'art i d'arquitectura que veié al llarg dels seus dos anys d'estada a l'illa de Mallorca. Josep Anton, però, tenia clar que el sentit últim del seu catàleg consistia a posar en valor la col-lecció que havia aplegat, amb l'esperança que els seus hereus sabrien apreciar, conservar i prosseguir la seva tasca - com, de fet, succeí-. Tant és així que, al Catálogo, hi apuntà la modesta voluntat de deixar un marge a cada foli per oferir-lo

[...] a las ulteriores observaciones y mas justas y juiciosas con que otros más inteligentes y doctos, puedan corregir lo que él ha puesto aquí, muchos de los cuales le han sido sugeridos por amigos, y por peritos que ya es sabido que sobre esta materia suelen ser pródigos de incienso. En símiles banquetes, grandes notabilidades han engullido gato por liebre, y él hubiera procurado digerir en silencio la porción que le haya quizás cabido, sin la esperanza de que la numeración de sus cuadros que confía heredarán y procurarán conservar sus hijos, les estimule á una afición tan inocente, tan noble, y tan agradable. Quiera Dios que así sea! ${ }^{26}$.

El catàleg manuscrit de Josep Anton de Cabanyes és el resultat d'un coneixement preclar de l'art de col-leccionar, que també traslladà a la seva ingent biblioteca. Prova d'això que diem és que, entre els llibres, hi havia els dos volums del Traité historique et pratique des connaissances qui sont nécessaires à tout amateur de tableaux et à tous ceux qui veulent apprendre à juger, apprécier et conserver les productions de la Peinture, suivi d'observations sur les collections publiques et particulières et de les Descriptions des tableaux qui propose en comment l'Auter François-Xavier de Burtinn ${ }^{27}$. No és gens casual que el tingués, perquè François-Xavier de Burtin, metge i físic, propietari d'un dels gabinets de curiositats més gran i extraordinari de l'Europa 
del seu temps, personatge rocambolesc i posseïdor d'una biografia novel-lesca, fou un dels grans difusors del coneixement de la pintura dels Països Baixos arreu d'Europa, especialment a França ${ }^{28}$. Del tractat de Burtin, se'n desprèn l'interès per descobrir l'autoria de l'obra, clau per determinar-ne l'estimació econòmica, però sense obviar-ne mai el valor implícit i qualitatiu del quadre. A les pàgines del primer volum de Burtin, hi sobresurt la idea que la pintura del seu temps, la de la segona meitat del segle XVIII, havia entrat en decadència; en canvi, les grans obres de temàtica històrica, basada en els principis del classicisme acadèmic dels segles XVI $\mathrm{i}$ XVII, era el model de la bona pintura.

No sabem si és casual o no, però, a la pinacoteca de Josep Anton de Cabanyes, hi abunden especialment obres de les escoles bolonyesa $\mathrm{i}$ romana dels primers anys del segle XVII - atribucions a Carracci, Reni, Poussin, Albani, Rosa, Guercino, Lanfranco, etc. - i obres de les escoles flamenca i holandesa de la fi del segle XVI i dels primers decennis del XVII. No estarà de més consignar-ne encara un altre detall: al volum segon del tractat del metge $i$ naturalista neerlandès, al capítol intitulat «Collections particulières: Méthode pour les bien former», hi ha suggerida una bella reflexió que ben bé podria haver guiat l'estimació que Josep Anton de Cabanyes sentia per la pintura -i que queda reflectida en les literàries descripcions que fa de cadascun dels seus quadres, un aspecte que cal consignar com una raresa del colleccionisme coetani, sovint molt magre en aquestes consideracions:

S'il est vrai que, parmi les passions nombreuses qui assiègent l'humanité, il en est beaucoup, qui ne s'emparent de l'homme que pour le jetter dans le malheur; il n'est pas moins vrai, qu'il en est d'autres, qui peuvent contribuer à son bonheur et augmenter sa félicité. Entre ces passions heureuses, aucune ne peut procurer, à l'homme dont elle s'empare une jouissance plus continue et plus durable, ni plus facile à communiquer sans frais aux autres, que celle qu'il éprouvera pour les tableaux! $!^{29}$.

Ras i curt, François-Xavier de Burtin, com també expressà contundentment Cabanyes a l'Advertencia, no es refiava dels «doctes ignorants» a l'hora d'elaborar el seu propi catàleg. S'estimava més ocupar-se'n ell mateix ${ }^{30}$.

Tot i que la sensibilitat classicista era ben present en els llibres de viatges de l'Europa il-lustrada i arreu del continent s'havia estès aquest corrent de retrobament amb els valors de la cultura clàssica grecoromana, el decantament classicista de Cabanyes, malgrat l'animadversió que sentia pels professors de Llotja, devia començar a Barcelona, on l'ideari d'Anton Rafael Mengs, difós pel diplomàtic José Nicolás de Azara i per personatges com ara Antonio Ponz des del si de la Real Academia de Bellas Artes de San Fernando, havien penetrat des del moment fundacional de l'escola de dibuix barcelonina ${ }^{31}$. Bona prova que Josep Anton de Cabanyes tenia coneixement directe de les colleccions barcelonines es troba justament en el comentari a la peça 57 del seu catàleg, descrit com a «Coloración de las Rosas. Copia del Albano. Escuela Lombarda»32. Josep Anton de Cabanyes fa notar que «[...] el original de este cuadro se halla en la Lonja de Barcelona de tamaño doble del de esta copia, la que tanto por la fidelidad del diseño, como por la delicadeza y brillo del colorido es digna de atención» ${ }^{33}$. Igualment, a l'hora de comentar la primera de les obres d'Antoni Viladomat de la Sèrie del patriarca Josep, no s'està de subratllar un dels principis bàsics de l'aprenentatge acadèmic que mancaven al pintor: «[...] los pocos conocimientos que tenía en Historia, y si carezca sobre todo de aquel bello ideal que se adquiera con el estudio de lo antiguo, y que tanto distingue a las Escuelas de Italia ${ }^{34}$. No estarà de més suggerir, encara, que, entre la seva extensa biblioteca, hi havia les Obras completas de Mengs $^{35}$, el Diccionario de Ceán Bermúdez ${ }^{36}$ i nombrosos títols de la cultura literària clàssica, com ara els de Pietro Bembo i Ariosto. Gli Asolani, de Bembo, un dels diàlegs arcàdics més cèlebres, marida perfectament amb el decantament del gust classicista cap a la mitologia i el paisatge, tan present en els quadres atribuïts a Albani, Poussin o Carracci que figuren a la colllecció de Josep Anton.

\section{Del(s) manuscrit(s) a les obres conservades}

Com bé ha explicat Bonaventura Bassegoda, la base de l'estudi del colleccionisme s'ha fonamentat en la documentació generada per les colleccions particulars a l'hora de passar a les públiques ${ }^{37}$. En el cas que ens ocupa, la cessió de la Masia Cabanyes per part dels descendents del pintor Alexandre de Cabanyes i Marquès ha permès disposar d'un patrimoni excepcional, tant des del punt de vista de la conservació de la quinta neoclàssica com de la dels béns mobles - pintures, llibres, documents, teixits, objectes, etc. - , una part important dels quals tenen a veure amb la pinacoteca original constituida per Josep Anton de Cabanyes, que fou continuada i ampliada pels seus descendents. No obstant això, i com és habitual, l'evolució dels patrimo- 


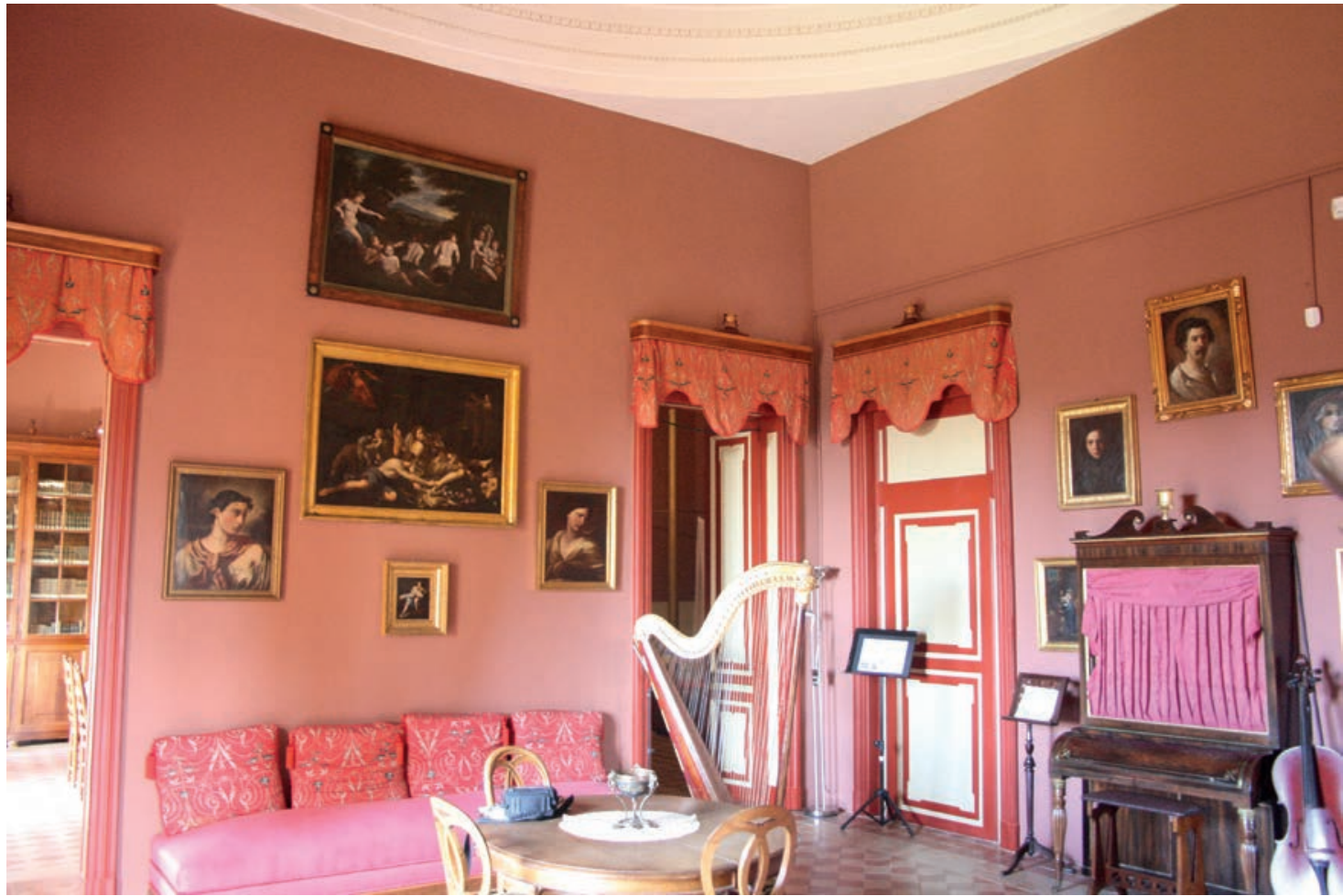

Figura 5.

Interior de la Masia d'en Cabanyes. Fotografia: Masia d'en Cabanyes. Arxiu fotogràfic del Centre d'Interpretació del Romanticisme Manuel de Cabanyes. Autors: Diego Calderon i Carles Andreu.

nis particulars no és mai lineal i hi juguen els avatars propis d'uns béns i d'unes possessions sotmesos als successos històrics, a les herències, als gustos, etc. És per això que el Catálogo és una font de primer ordre. Fou elaborat al final de la seva vida, cap a I 850 , ja que Josep Anton hi consignà un seguit de quadres del seu germà Joaquim de Cabanyes, pintor i militar, que corresponen a les seves estades a Alcalá de Henares i a Segòvia, com també al seu pas per Mallorca. A l'illa, Joaquim hi pintà una vista del Castell de Bellver, que fou inclosa $i$ comentada al catàleg. Si Joaquim anà a l'illa el I 850 i Josep Anton morí el i 852 , la data d'elaboració del catàleg ha d'estar en aquest període de dos anys.

El Catálogo, tot i que es tracta d'una font de gran utilitat per reconstruir la colllecció original, no resol alguns dubtes importants, com ara quines obres foren adquirides per Josep Anton i quines ja provenien, si és que és el cas, del seu pare o de la casa Cabanyes d'Argentona, d'on eren originaris els Cabanyes vilanovins. Tampoc dona gaires informacions sobre on comprà les obres, si a París, als mercats italians, a Brussel-les, a Amsterdam o a Barcelona. Amb tot, alguns dels interrogants de la formació de la col-lecció poden tenir resposta en un altre manuscrit de Josep Anton, ja conegut per Rius i Vila, però a hores d'ara pendent de ser editat enterament. El manuscrit en qüestió és una re- lació de notícies de l'estirp dels Cabanyes aplegada pel nostre personatge, la major part de les quals es refereixen a compravendes de terres, però farcida de dades biogràfiques i successos viscuts pels diferents membres de la família, a la manera d'un dietari personal. El fragment que ens n’interessa diu així:

[...] i de enero de i84i. Dn. José Antonio, su Señora Madre, su Esposa e hijos salieron de Barcelona para regresar a sus hogares. No podemos menos de anotar aquí, que al regresar D. José Antonio con toda su familia a su casa paterna después de seis años de peregrinación y destierro ha tenido todavía el gusto de llevarse consigo una porción de cuadros antiguos y preciosas pinturas al óleo que con su particular afición ha recogido durante su permanencia en Barcelona donde tales objetos son poco apreciados de sus bárbaros moradores, y librándolos así de la constante pesquisa que de ellos hacen los Extranjeros. Unidos estos cuadros a otros que ya poseía ha formado una pequeña colección, que es sin duda el más bello adorno de su Casa, que espera todavía aumentar, y que sus Hijos sabrán conservar y aumentar asimismo. El Catálogo de ellos se halla en la Biblioteca de la Casa de Villanueva. Dicha Biblioteca se compone de pasados tres- 
cientos volúmenes, la mayor parte recogidos por D. José Antonio, muchos ya lo fueron de su Señor Padre, algunos otros por su hermano D. Manuel, y algunos también por su Tío D. José María. Así mismo se halla allí el Catálogo de las obras que la componen ${ }^{38}$.

De la informació de las Notícias, se'n pot deduir que una part de la col-lecció ja la tenia abans de I 835 , data en què es veié obligat a tapiar la Masia d'en Cabanyes, tancar la casa de la plaça de les Cols i emprendre un pelegrinatge que el dugué a Mallorca i a Barcelona, fugint de la inestabilitat provocada per les escaramusses de les guerres carlines. A diferència de la biblioteca, però, no esmenta que els quadres que ja tenia provinguessin del pare o de l'oncle. És força probable, doncs, que n'hagués atresorat una part durant els seus viatges per Europa: les pintures sobre superfície de coure - habituals de les escoles holandesa i flamenca - i segurament una bona part dels llenços que es poden adscriure a l'àmbit italià formarien part d'aquest lot de compres foranies $^{39}$. Gràcies a les anotacions del Catálogo, sabem que, a Barcelona, hi comprà la Sèrie de la vida de Josep, d'Antoni Viladomat, $\mathrm{i}$ és probable que n'hi adquirís algunes més, ja que la Barcelona de les revoltes de I $_{3} 5$ i de la desamortització posterior es convertí, com recorda Padró, en un mercat artístic freqüentat per àvids compradors arribats d'arreu d'Europa, com ara el baró de Taylor: «[...] qui era a Barcelona el I 835 comissionat pel rei francès Lluís Felip: ell mateix ens diu com va adquirir a ínfims preus molts quadres $i$ altres objectes artístics provinents dels convents saquejats» ${ }^{40}$. El I 844 , en una carta dirigida al seu germà Joaquim, Josep Anton li diu que, si hagués sabut que es trobava a $\mathrm{Va}$ lència, li hauria fet enviar «un cuadrito que tengo que necessita un poco de restauración, y en la culta Barcelona son gente que lo entienden poco [...] Si hallases alguna cosa bonita que no fuera asunto de onzas sino de duros, recógelo por cuanta mia, pues aquí es país esteril» ${ }^{41}$. Aquesta carta dona idea de l'animadversió de Josep Anton per Barcelona, però també de la seva afició per aconseguir noves obres susceptibles d'augmentar la seva col-lecció, en aquest cas, a través del seu germà Joaquim.

Tot i que la qüestió de la ubicació original dels quadres no està del tot clara, diversos documents permeten fer-nos una idea d'on estaven emplaçats. Segons la citació de I84I, n’hi havia alguns a Barcelona, a la casa del carrer de Mercaders, una part dels quals se'ls endugué, juntament amb els que havia adquirit durant la seva estada a la Ciutat Comtal, cap a Vilanova i la Geltrú. Però no pas a la Masia d'en Cabanyes, sinó a la casa de la plaça de les Cols. El i 844, entremig de les pàgines més emotives del dietari, que expliquen la mort de la seva esposa, Josefa d'Olzinelles i de Romero, que engendrà sis fills, hi ha una breu descripció de Can Cabanyes de Vilanova:

[...] Al declinare el sol, se levantó para trasladarse al cuarto Principal del Primer Piso. [...] Con un intento de evitar que el aire pudiera dañar a Dña. Pepita, su Esposo le cubrió la cabeza y toda su persona con una ancha cubierta oscura, que estaba allí a la mano, y cogida de su brazo, pues que aquel manto le impedía la vista, la hizo pasar por el cuarto de los cuadros ${ }^{42}$.

El «cuarto de los cuadros» era el saló principal de Can Cabanyes de Vilanova, on devien estar col·locats segons la museografia pròpia de l’època (figura 5), és a dir, en alçada i segons la disponibilitat que oferien els espais lliures de les parets. Al mateix manuscrit familiar, s'hi esmenta que la casa de Vilanova, que havia comprat el seu pare i que havia fet embellir pel pintor Solanes, estava decorada amb mobles $\mathrm{i}$ pintures de bon gust, que Josep Anton degué completar. En realitat, a la casa del poble és on passaven més temps i des d'on a les tardes sortien a passejar fins a la Masia d'en Cabanyes.

Tres documents més donen fe d'aquesta dispersió de les obres, però, per raons d'extensió, ens és impossible d'abordar-los amb detall en el present article. El primer és el propi testament de Josep Anton, on llegim que, a la casa de Vilanova, hi havia «una colección de ochenta y dos cuadros al óleo», la major part dels temes dels quals - prossegueix el document notarialestan explicats $i$ anotats al Catálogo ${ }^{43}$. L'altre font és l'inventari de béns de I895 del seu fill Llorenç de Cabanyes i Olzinelles, que, en un extensíssim protocol, detalla el repartiment dels béns mobles i immobles de la seva propietat. Les pintures, com en el testament del seu pare, es trobaven principalment a la casa de la plaça de les $\mathrm{Cols}^{44}$. El tercer document és un inventari amb un apèndix, avui només conegut pel mecanoscrit realitzat per Joan Rius el 1957, en què Josep Anton ressenya novament les obres de la seva col-lecció (apèndix documental 2). Aquest inventari, realitzat després del Catálogo, inclou una frase a l'encapçalament que diu «Los números señalados con $\mathrm{X}$ están en Barcelona». Quaranta-sis dels noranta-vuit quadres - setze més del total ressenyat al Catálogo- porten la marca que els situa a la casa de la Ciutat Comtal. La hipòtesi més versemblant que explicaria el moment en què els quadres passaren a Can Cabanyes és quan Carles i Alexandre de Cabanyes, fills de Llorenç de Cabanyes i Olzinelles, es repartiren el llegat. La quinta neoclàssica de 


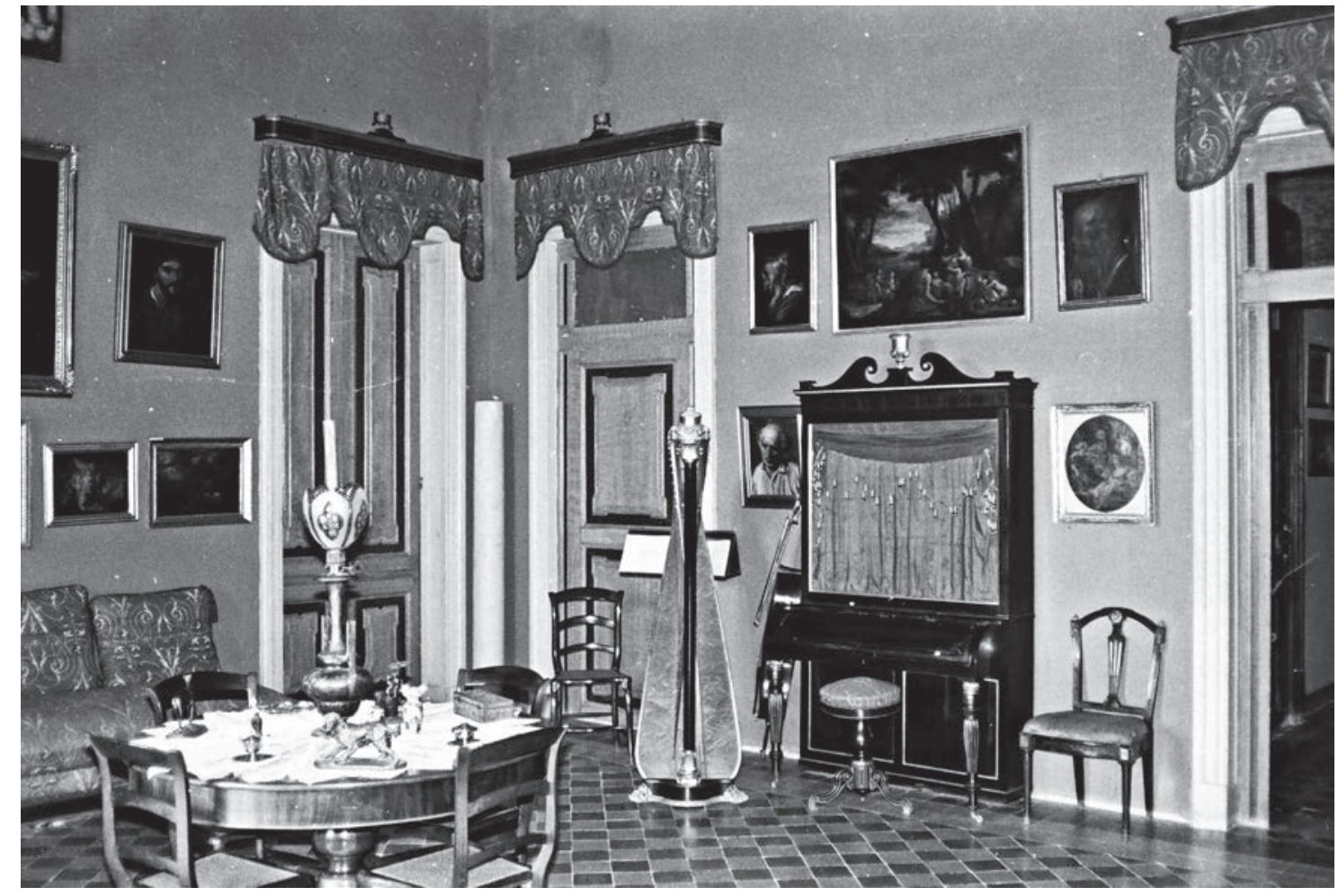

Figura 6.

Fotografia de la sala dels quadres. Fotografia: ACG, Fotografia d'Antoni Monrós i Valls (donació de Ricard Monrós).

la Masia d'en Cabanyes i la pràctica totalitat dels quadres de la col-lecció original traspassaren a Alexandre de Cabanyes (figura 6).

Pel que fa a les característiques del Catálo$g 0^{45}$, direm que està conformat per $7 \mathrm{I}$ folis - numerats amb posterioritat - que contenen descripcions amb tinta negra de 82 obres de la collecció, perfectament numerades de forma correlativa, que l'autor diu que obeeix a l'ordre d'adquisició de cadascun, malgrat que aquesta afirmació és difícil d'acceptar, perquè els primers quadres són les obres de Viladomat i, com hem vist a les notes de I84I, ja tenia una petita col-lecció prèvia. La cal-ligrafia regular de la totalitat del manuscrit fa pensar que totes i cadascuna de les entrades són fetes per Josep Anton, malgrat que algunes anotacions entre parèntesis amb la paraula Cambiado n'indiquen un ús posterior. El manuscrit està enquadernat en tapa dura o cartoné, en posició vertical, i la coberta presenta decoració d'aigües en tons grisos. Té el llom i les cantonades decorades amb cartó de color verd i presenta guarda amb paper, també amb aiguades de colors suaus. En el llom, no hi ha cap inscripció. Els fulls tenen un marge a la banda esquerra per tal de poder fer-hi anotacions - quan hi són, estan realitzades amb llapis-. Al revers de la primera pàgina, amb llapis, hi ha anotat «Retrato $\mathrm{M}$. de Cabanyes. Es de Espalter», que recorda la lletra
d'Alexandre de Cabanyes ${ }^{46}$. El títol del manuscrit es troba a la segona pàgina, fet amb llapis. $\mathrm{Al}$ revers de la segona pàgina hi ha una consideració que revela clarament la naturalesa de la font i el tarannà del seu propietari. Diu així:

Advertencia. El Epígrafe que se ha puesto al principio de esta descripción indica claramente que quien la hizo estaba en el país de la Desconfianza, y se nutría muy a menudo y a sabiendas de ilusiones. El espacioso margen que ha dejado á cada página, la ofrece a las ulteriores observaciones y mas justas $\mathrm{y}$ juiciosas con que otros más inteligentes $\mathrm{y}$ doctos, puedan corregir lo que él ha puesto aquí, muchos de los cuales le han sido sugeridos por amigos, y por peritos que ya es sabido que sobre esta materia suelen ser pródigos de [...]. En símiles banquetes, grandes notabilidades han engullido gato por liebre, y él hubiera procurado digerir en silencio la porción que le haya quizás cabido, sin la esperanza de que la numeración de sus cuadros que confía heredarán y procurarán conservar sus hijos, les estimule á una afición tan inocente, tan noble, y tan agradable. Quiera Dios que así sea!

L'epígraf en qüestió és una citació de Walter Scott, que, ras i curt, diu: «Every virtuoso 


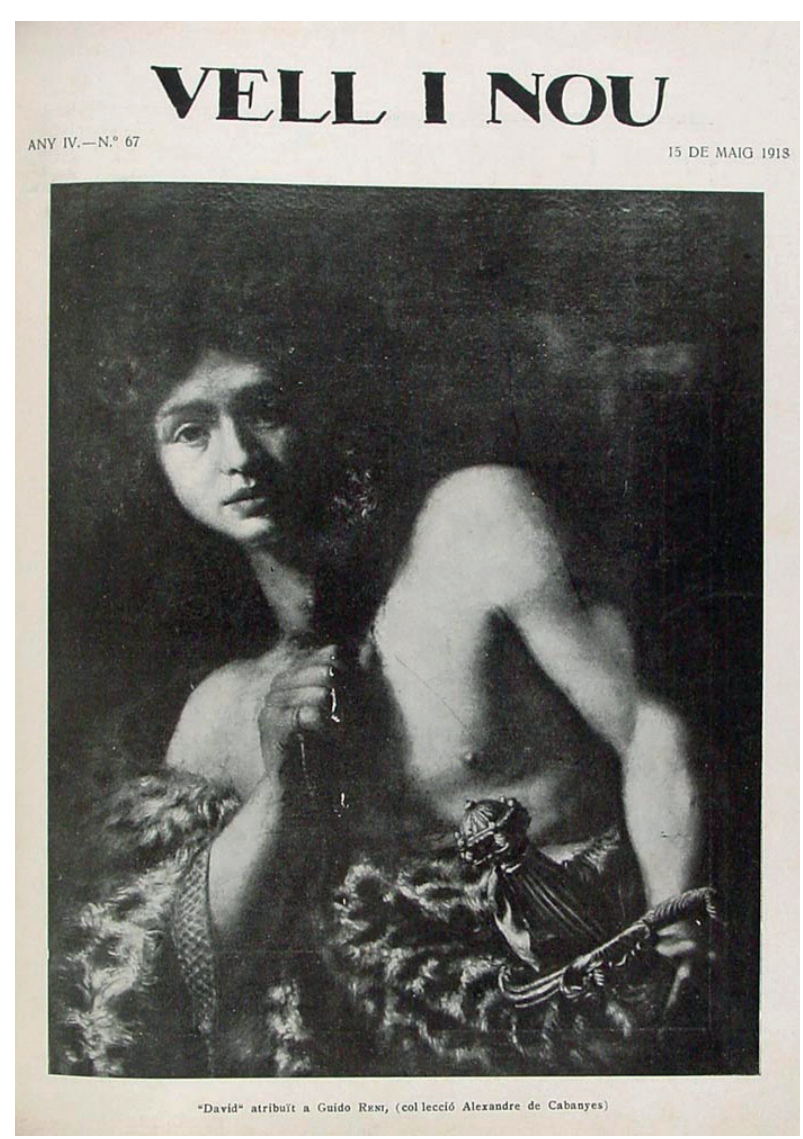

Figura 7.

Anònim d'escola bolonyesa, David. Fotografia: revista Vell i Nou.

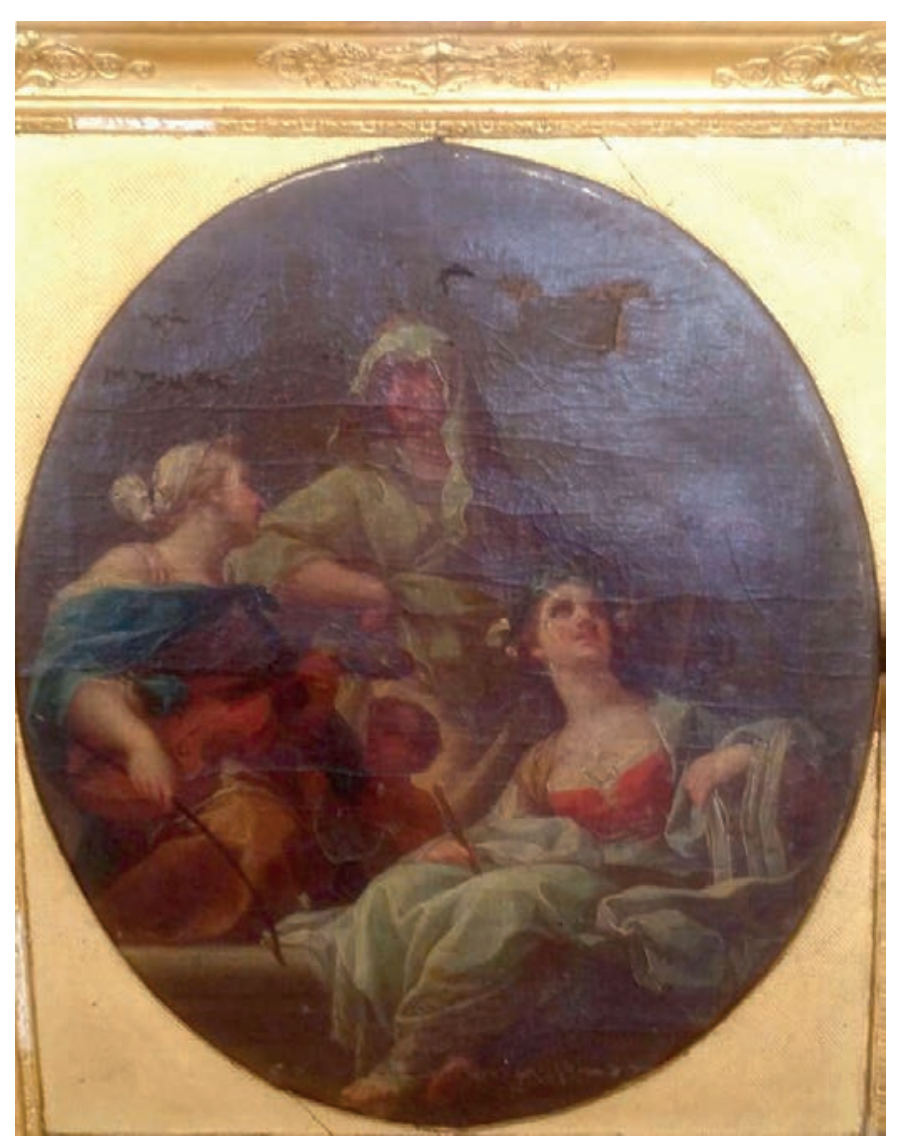

Figura 8.

ANÒnIM (cercle de M. S. Maella), Tres muses, col-lecció Pilar Ochoa. Fotografia: Albert Alentorn. do imagine that all his gooses are swans / Los aficionados suelen figurar que todos sus gansos son otros tantos cisnes (Walter Scott) [sic]». Aquesta màxima ens va prou bé per comprendre la importància que Josep Anton atorgava al document, conscient que tindria un valor testimonial i, al mateix temps, pedagògic per als seus futurs descendents. És per això que, més enllà del punt de vista quantitatiu, del document és interessant subratllar-ne el seu alt valor literari. Josep Anton és capaç d'apreciar en les seves obres aspectes que tenen a veure amb el seu propi gaudi, amb el gust estrictament personal que sent davant la contemplació de les obres. I no només això: al llarg de les entrades, hi ha abocada, amb un llenguatge refinat però gens ampul·lós, la seva amplíssima erudició, que acompanya de comentaris que traspuen les seves lectures i la seva experiència viatgera. No es estrany, en aquest sentit, que a vegades assoleixi un tipus d'observacions que traspassen l'afició col·leccionista i que l'apropen a la figura del crític d'art o de l'historiador.

Per concloure, només ens queda subratllar que la identificació de la totalitat de les obres aplegades per Josep Anton de Cabanyes és una tasca molt complexa, ja que que no s'han con- servat totes i, a més, un paquet important, ja en data desconeguda, havien estat bescanviades o venudes en vida del seu últim propietari, com ara una obra atribuïda a l'escola bolonyesa de Guido Reni, que apareix reproduïda a la revista Vell $i$ Nou de I9I 8 (figura 7) ${ }^{47}$, o una bella pintura que ja apareix a les fotografies del fons Català Roca de l'arxiu del Col·legi Oficial d'Arquitectes de Catalunya que serviren per il-lustrar el llibre de Camps i Arboix sobre les cases pairals catalanes, a la sala on hi havia l'arpa (figura 8$)^{48}$. Es pot seguir el rastre d'algunes d'aquestes obres "desaparegudes» amb l'ajuda dels materials d'hemeroteca i de les fotografies antigues, com també a través de dos documents més: una taxació realitzada el 6 d'octubre de 1973 per Josep Gudiol ${ }^{49}$, que inclou les obres que passaren a Joaquim, Marta i Neus de Cabanyes, hereus d'Alexandre, i una taxació de 1974 que s'adjuntà a l'acta de cessió de la Masia de $1975^{50}$. Als apèndixs documentals, hi hem ressenyat les obres que hem pogut identificar i que es conserven, anotant-ne el número d'inventari general de la Masia d'en Cabanyes i unes altres ubicacions externes, alhora que hi hem aportat comentaris d'índole historicoartística. 


\section{Apèndix documental I}

\section{Catálogo y descripción de algunos quadros que posee Dn. José Antonio de Cabanyes (c. I 850 )}

Manuscrit de l'Arxiu de la Masia d'en Cabanyes. Vilanova i la Geltrú

[Nota: s'ha respectat la sintaxi del text original. Entre claudàtors hi hem afegit anotacions i observacions. Quan es coneix la ubicació actual de l'obra, s'indica amb una nota a peu de pàgina.]

$\mathrm{N}^{\circ}$ I ${ }^{*}$ ). José vendido por sus hermanos. De Viladomat. Harta conocida es de todos las historias de José y sus hermanos. El insigne Viladomat honor y gloria de Cataluña $(* *)$ la tomó por asunto de una serie de cuadros (el del presente número y los seis siguientes) que sin duda alguna es una de sus mas bellas producciones, ó quizás la mas bella, después de las grande y admirable galería de Sn Francisco de Asís trasladada hoy día en la Lonja de Barcelona, y de los cuadros magníficos que hay en la Capilla del Sacramento de Mataró. Si las obras del pintor catalán descubren por lo común los pocos conocimientos que tenía en Historia, y si carezca sobre todo de aquel bello ideal que se adquiera con el estudio de lo antiguo, y que tanto distingue a las Escuelas de Italia; superabunda por otra parte de tanta naturalidad, y de tanta verdad, que por doquier se ve al genio remontarse sin apoyo ni guía, al punto de excitar la mayor admiración y marcar los más justos aplausos. Así lo muestra este primer cuadro cuya composición no pueda ser más bonita ni mas natural ni expresiva la postura sobre todo del infeliz mozo, que sacan del aljibe para ser vendido por sus propios hermanos. Uno de los Medianitas lo coge del brazo como con señal de posesión mostrando su semblante mas humanidad que el de los crudos hijos de Jacob tan solo atentos al cobro del precio de su crimen. Los rebajados son asimismo muy bien executados, y solo falta que algunos escorzos fuesen mas trabajados, para que este lienzo pudiera ser tenido por una obra admirable. Las figuras son de dos terceras partes de cuerpo y de tamaño natural. Este cuadro tiene de alto 3 piés con Io pulgadas y de ancho 5 piés con 7 pulgadas ${ }^{51}$.

(*) En esta enumeración se ha seguido el orden de adquisición que ha hecho de los cuadros su actual poseedor.

$(* *)$ No se puede decir de la Escuela Catalana, pues aunque Viladomat tuvo hijos y discípulos que se distinguieron en la pintura, ni estos fueron muchos, ni dejaron otros discípulos, ni todos juntos con otros pintores catalanes se han hecho conocer por un genio y carácter particular, que pueda merecer en nombre de Escuela.

$\mathrm{N}^{\circ}$ 2. Los hijos de Jacob le presentan la túnica ensangrentada de José. De Viladomat. Esta composición es bella y admirable como la precedente y la gran expresión de todas las figuras y la verdad que reina en todas sus partes, le hacen disimular algún tanto de dureza , tan común en casi todas las producciones de este autor. Tiene el mismo tamaño que el precedente.

$\mathrm{N}^{\circ}$ 3. Josef huye de la Putiphar. De Viladomat. Este cuadro es sin duda alguna el mejor de esta serie. La perfecta composición, el correctisimo dibujo, el bien entendido claro obscuro, y sobre todo el hermosisimo colorido lo manifiestan. Es admirable en particular la candidez que respira el semblante del mozo Joseph. También son los escorzos muy bien executados, y la suavidad que reina en todo el cuadro le distingue de las demás obras del autor, tildado de algún tanto de dureza. Es del mismo tamaño que las dos precedentes.

$\mathrm{N}^{\circ}$ 4. Joseph en la carcel. De Viladomat. Al solo aspecto de los personages que componen este cuadro, se adivina des de luego su futura suerte; ó mas bien su anterior conducta. En efecto la fachada adusta, y postura fiera del panadero, indican ya un hombre capaz de crímenes, y destinado al suplicio; al paso que un buen natural se descubre en las fisionomías del copero, quien hallará en breve gracia ante su señor. Asi se lo predica Joseph en cuya figura rebosa la candidez, la inocencia y la resignación. Mas lo singular de este cuadro consiste, en que no solo el artista nos pinta con mano maestra la situación de los animos, sino que hasta nos quiso hacer visibles los sueños que están contando los dos empleados de Pharaon, poniendo sobre las espaldas del uno el canastillo de Partas y la copa en la mano del otro. Entre las muchas bellezas de este lienzo se distingue el bien entendido musculado del panadero y la suavidad del colorido de Joseph. Es del mismo tamaño que los precedentes». [Al marge, hi ha una anotació que diu: «[Falso?] se quemó». $]^{52}$.

$\mathrm{N}^{\circ}$ 5. Joseph explica el sueño de Pharaon. De Viladomat. Esta es quizás la pieza mas floxa de la presente serie no siendo posible que en una obra tan dilatada se mantenga el genio constantemente à una misma altura; y no dormite cual el del inmortal Homero, una vez que otra: mas no obstante se descubre todavía en ella la mano del hábil artista que lo trazó. Es del mismo tamaño que sus precedentes compañeras.

No 6. Joseph atemoriza á sus hermanos. De Viladomat. Cumpliose el sueño de Joseph, quien, asi como antes se le figuró ver la gavilla que él hacía en el campo, adorada por las que hacían sus hermanos ve ahora á estos, que postrados á sus piés le adoran. Hermosisima es esta composición y del mayor efecto. El terror esta pintado en el semblante de los hijos de Jacob y la memoria de su proceder atroz para con su hermano, que sin saberlo, tienen delante, les agobia, y lo miran como la causa de la dura situación en que ahora se hallan. Pero lo que más admira en este lienzo es la figura de Joseph, en la que se trasluce su ternura al través de su aparente 
severidad y dureza. Asi es que el artista nos lo ofrece con la vista fina y desviada de sus hermanos, como para indicarnos que al instante que la volviera hacia ellos no seria ya mas dueño de sí. La verdad, y la expresión, calidad que tanto distinguen el pincel de Viladomat, se hallan aquí á un grado eminente. Tiene las mismas dimensiones que los precedentes.

$\mathrm{N}^{\circ}$ 7. Joseph se da a conocer á sus hermanos. De Viladomat. Simil escena que la del numero precedente. Se nos ofrece en el presente, aunque animadas con sentimientos del todo diversos y expresados con tanta ó mas habilidad y maestria. En efecto, en lugar del duro superintendente contemplamos aquí al tierno hermano, que olvidando las pasadas injurias se da por fin á conocer, y cierra ya entre sus brazos á Benjamin. Dificil seria agrupar mas propiamente á los dos hijos de Rachel, y dar mas expresión y gracia á sus bellísimas fisionomías. Es admirable asi mismo la variedad de semblantes, y bien estudiadas posturas de los demás hermanos, al paso que todos [?] La sorpresa, el arrepentimiento y el gozo que simultáneamente debía conmover sus pechos. Este lienzo es el ultimo de la serie y tiene las mismas dimensiones que sus precedentes compañeros.

Nota. No será fuera del caso anotar aquí, que estos siete cuadros los compró su actual posesor por un precio tan vil, que seguramente no llegaba de mucho á lo que costaron los antiguos marcos que los guarnece; Siendo de advertir que no fue una venta clandestina, ni trato con gente que no conocía el genero, pues fueron comprados en una de las tiendas mas publicas de Barcelona y después de haber permanecido allí largo tiempo sin presentarse quien ofreciera un cuarto por ellos. Los pintores de La Lonja los conocían, y los ilustres señores de aquella Junta titulada Protectora de las Bellas Artes, no hallaron á bien emplear 24 duros para aumentar su miserable museo. ¡Tal es la ciudad que con ridículo empeño denominan culta!

$N^{\circ}$ 8. Pais. Vista de un Molino sobre el Henares en las cercanías de Alcalá. De Dn. Joaquin de Cabanyes. Este bello paisito, primicias del pincel de un aficionado, de quien el afecto lo dedicó á su hermano, se distingue particularmente por el tono caliente que le cubre y por su hermoso colorido. Tiene de alto 6 pulgadas con 5 lineas, y de ancho 8 pulgadas ${ }^{53}$.

$\mathrm{N}^{\circ}$ 9. Pais. Vista del castillo de Bellver en Mallorca. De Dn. Joaquin de Cabanyes. Hermano mellizo del precedente, ofrecido y aceptado por el mismo fraternal cariño es también este paisaje apreciable por la harmonia de su colorido. Es del mismo tamaño que el precedente ${ }^{54}$.

$\mathrm{N}^{\circ}$ io. Noche de luna. De Dn. Joaquin de Cabanyes. Este paisaje está tocado con mucha habilidad y gusto; y el celage es muy bello. La idea de iluminar una parte que queda privada de la luz de la luna con la de una hoguera à la que se calientan unos soldados, es sumamente feliz y aguantada con mucho acierto, formando un bello contraste lo blanquecino de los rayos lunares con lo roguizo de los del fuego. Tiene de alto 9 pulgadas y i y media de ancho ${ }^{55}$.

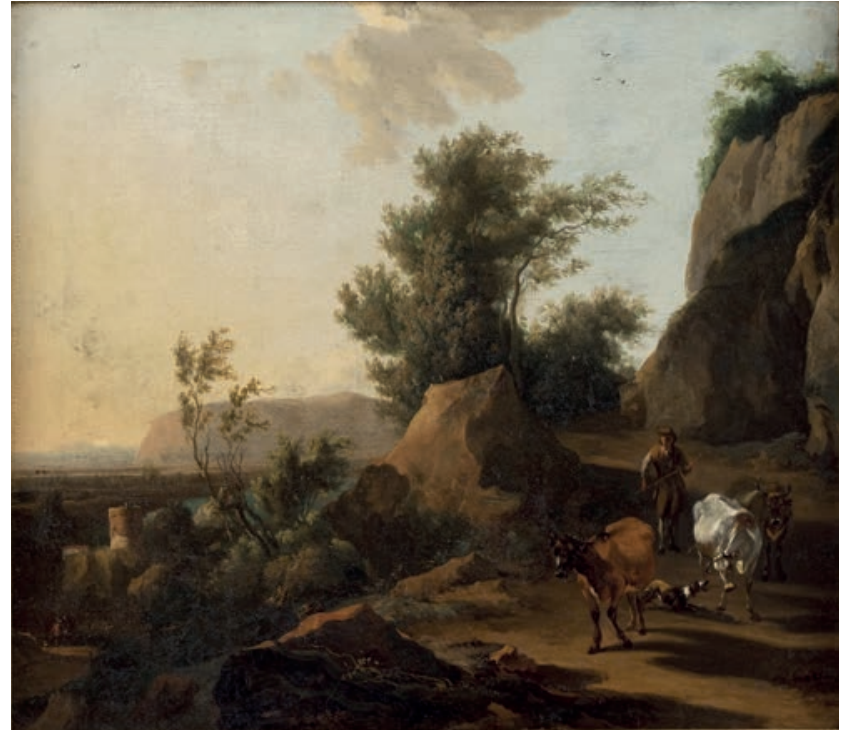

Figura 9.

Atribuït a Claude Joseph Vernet, Paisatge amb bous i pastor, Masia d'en Cabanyes. Fotografia: Carles Aymerich, CRBMG.

$\mathrm{N}^{\circ}$ i r. San Francisco de Paula. De la Escuela de Viladomat. Figura de tamaño natural y de medio cuerpo. Tiene de alto 2 piés con 3 y media pulgadas, y de ancho I pie con I I pulgadas ${ }^{56}$.

$\mathrm{N}^{\circ}$ I 2. Anacoreta en oración. De autor desconocido aunque lleva el nombre de Joannes y parece ser de la Escuela Valenciana. El viejecito que se ve leyendo dentro de la cueva está colocado con mucha propiedad, y las peñas, troncos y malezas que le rodean, son ejecutadas con verdad y maestria. El tono del colorido es muy bonito y tiene mucha armonía, siendo de sentir que una mano inexperta y atrevida haya estropeado (quizas queriéndolo limpiar) el pié del Hermitaño, y la parte del cuadro que presenta una perspectiva lejana. Es pintado sobre cobre y tiene de alto 7 pulgadas con 4 lineas y de ancho 9 pulgadas con 8 lineas.

$\mathrm{N}^{\circ}$ I3. Hércules matando un león. De autor italiano. Estudio al natural. Tiene de alto 2 piés con 3 pulgadas y de ancho 2 piés con 8 pulgadas. [Anotació on diu «cambiado».]

$\mathrm{N}^{\circ}$ I4. Pais con un Boyero [figura 9] Del padre y maestro de Claudio José Vernet. Escuela Francesa. Este hermosísimo paisaje se distingue por la harmonia de su ardiente colorido, y los arboles que graciosamente coronan el peñasco del centro están llenos de aire y ligereza. El pastor y las tres vacas, sobre todo la que está retozando con el perro dan mucho movimiento á la composición, y la grandiosidad de las peñas que hay á la derecha la hacen magnifica. Tuvo que forrarse este lienzo á causa del estado deteriorado en que se encontraba. Tiene de alto un pié con I I y media pulgadas y de ancho 2 piés con 3 pulgadas ${ }^{57}$.

$\mathrm{N}^{\circ}$ is. Marina. De Salomon Rusidaal de Harlem. Escuela Holandesa de mediados del siglo $17^{\circ}$. Una brisa parcial tan común en los mares del Norte, remueve la 


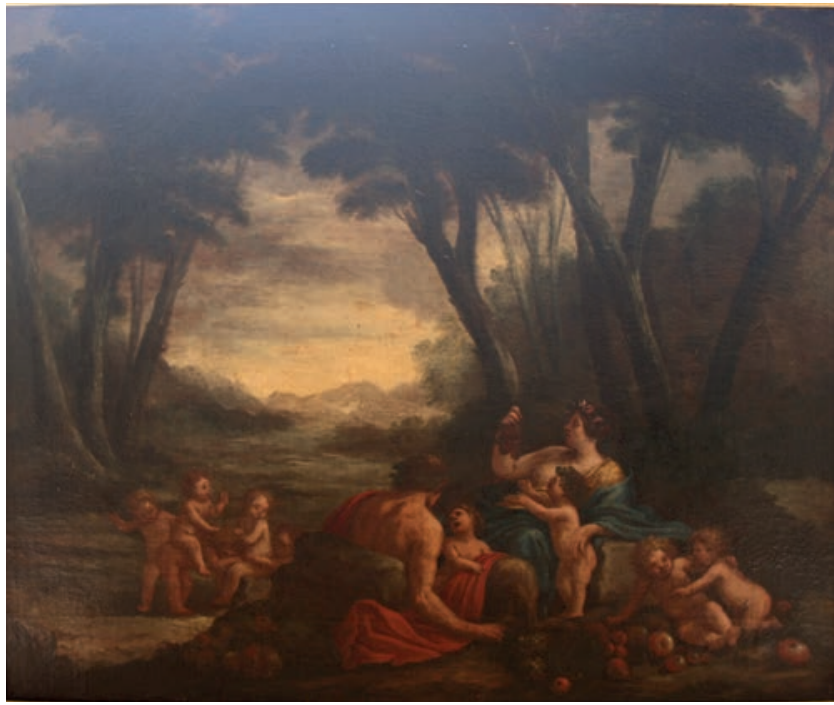

Figura 10.

Anònim d'escola romana, Vertumne i Pomona, col·lecció Pilar Ochoa de Cabanyes. Fotografia: autor.

parte del mar que está en el primer plano, y que forma como una grande Bahia, hinchando las altas velas de una hermosa Urca holandesa y haciendo saltar la canoa de unos pescadores que recogen sus redes, al paso que a lo lejos la calma de las aguas, las hace casi confundir con el horizonte. El celage está en conformidad con este contraste de la mar pues mientras que una densa niebla se levanta y se estiende al soplo de la brisa y cubre la parte anterior del cielo, la posterior se ve adornada de unas hermosas nubes semidoradas por la luz del sol, seguro indicio de la mas completa bonanza. A lo lejos se descubren las Dunas ó montecillos de arena que defienden la Provincia de la Norte Holanda del furor del Oceano del Norte. A la izquierda y en primer termino se ven á unos marineros que desembarcan efectos de un Yacht del cual se descubre solo el velamen. El tono plateado de este paisaje es sobre todo admirable. Tiene de alto I pié con I I pulgadas, y de ancho 2 piés con 5 pulgadas ${ }^{58}$.

$\mathrm{N}^{\circ}$ i6. San Pedro. Escuela de Viladomat. Tiene de alto un pié con 5 pulgadas, y de ancho un pié con 2 pulgadas. [Anotació on diu «Cambiado».]

$\mathrm{N}^{\mathrm{o}}$ i 7. Sacra Familia. Copia de un hermoso cuadro del Correggio que posee el Sr. Marqués de Castellvell en Barcelona. Una mano inexperta ha deteriorado esta pintura queriéndola limpiar sin duda. Es pintado sobre cobre de forma ochavado, y tiene de alto ro pulgadas y de ancho 9 pulgadas con 5 lineas. [Anotació on diu «Cambiado».]

$\mathrm{N}^{\mathrm{o}}$ i 8. David vencedor de Goliat. De Guido Reni. Escuela Boloñesa. El Pastor David, representado a lo heroico tiene desnudo el pecho, espaldas y brazos, y solo una piél de tigre, le cubre el resto del cuerpo, el cuadro no presentando mas que media figura. Con la mano derecha tiene asida la cabellera del Gigante Goliat, cuya cabeza cuelga detrás de la espalda de su vencedor. Al mismo brazo derecho se vé entorchado un extremo de la piél de tigre, y la honda de pastor; a la mano izquierda lleva la espada del Filisteo como en trofeo y señal de su victoria. La belleza de este cuadro es estrema sobre todo en la blandura y suavidad de sus carnes; pero lo que le da más realce es la grandiosa postura de cabeza del héroe y la nobleza de sus facciones, parte en que tanto sobresale el autor. Tiene de alto 3 piés con dos pulgadas y de ancho dos piés con 7 pulgadas ${ }^{59}$.

$\mathrm{N}^{0}$ i9. Jesús sentado en una cathedra. De Agustin Caracci. Escuela Bolonesa. Ya que no sea fácil hallar en la vida de N. S. Jesuchristo detallada en los Santos Evangelios con pasage que explique directamente el asunto de este cuadro, es probable que el pintor quiso representarnos el momento cuando la famosa Mujer de Magdala instada ya por un movimiento interior y guiada por una de las Santas mujeres que solian seguir al Salvador, ó quizás por su misma Madre Santisima, fue al templo, y escuchó por primera vez de la boca del Señor la doctrina de amor y de consuelo. En efecto vemos á Jesús sentado en una silla magistral desde donde parece que predica al pueblo; pues que à su lado y en primer plano se halla un oyente que el artista ha pintado casi de espaldas, al paso que ve á su frente se á una mujer joven bella, y ricamente ataviada, que casi no puede ser otra que la pecadora Magdalena, acabando de descubrirla el profundo arrobamiento que está marcado en su semblante, y que es ya el principio de su conversión. A su lado se haya otra mujer que parece ser su guía, cuyo humilde y obscuro trage indica cuan poco participa de las vanidades de esta vida, mientras que la aureola que la corona muestra que ya está destinada a las glorias de la otra. Esta bellísima composición no desmiente en nada la fama de su autor, tan celebre por su elegancia y sobre todo por la corrección de su Dibujo. En particular la fría Magestad del Redentor, y el pasmo de la convertida forman un hermoso contraste. Este cuadro parece haber sufrido algún escalabro, cuyo restauro no ha sido muy feliz, pues que es harto visible en el manto de la Santa mujer, y en laguna parte del fondo. Tiene de alto 2 piés con 6 y media pulgadas, y de ancho tres piés.

$\mathrm{N}^{\circ}$ 20. Pais [figura Io]. De Nicolas Poussin, pintor Francés, aunque mirado como de la Escuela Romana. A pesar de que la mayor parte de este cuadro haya quedado en bosquejo, no obstante hay tanta grandeza y maestria en su execucion, y tanta seguridad en los toques, que por doquier se patentiza al grande artista. Las figuras parecen representar a Pomona teniendo entre sus brazos y ofreciendo al niño Baco el fruto que les es tan grato; al paso que otros niños ó genios juegan con varios frutos ó se divierten en exercicios infantiles. Vertumno recortado frente de su amada Dea, y coronadas también sus sienes parece participar de la común alegría, y del gozo que da la contemplacion de la fertilidad de la Tierra. Quizas la principal idea del artista fué manifestar con una alegoría esta fertilidad y belleza. Tiene de alto 3 piés con 2 pulgadas; y de ancho 3 piés con 2 pulgadas ${ }^{60}$.

No 2 I. Sta. Catalina de Sena. De Francisco Zurbarán. Escuela Sevillana. Una bellísima frescura de colorido, y una fervorosa expresión hacen interesante la figura de la Santa cuya alma parece del todo embebida en la 
contemplacion de un crucifijo que tiene en las manos, Los ropajes son asimismo muy bien entendidos y el solo aspecto se distingue la calidad de los varios texidos que los componen. Es muy bien tocado el cráneo y demás accesorios que hay en este cuadro. La figura de la santa es de medio cuerpo y de tamaño natural. Tiene de alto 3 piés con una y media pulgada; y de ancho 2 piés con $5 \mathrm{y}$ media pulgadas ${ }^{61}$.

$\mathrm{N}^{\mathrm{o}}$ 22. Marineros con una Muchacha. De Viladomat. Este gracioso Bosquejo está lleno de aquella naturalidad que tanto caracteriza el pincel de este insigne pintor catalán. Cuatro picaros marineros parece que tratan de persuadir á una sencilla aldeana á que se embarque en un esquife que tienen atracado al muelle, y sus fachas ya indican con cual intento. Los tres la tienen casi asida, al paso que el otro tiene empuñados los remos para alargarse al instante que la inocente ponga el pie en el bote. Ello no acaba de resolverse, pero está tan embarcada con alhagos y ofertas de sus galanes que el huso se le ha caído ya de la mano, y la rueca vuelta hacia abajo, es cual amainado pavellon de combatida corbeta que da la primera señal de rendirse. Todas las figuras estan admirablemente agrupadas. Este cuadrito está pintado sobre papel y pegado no muy bien sobre una tabla. Tiene de alto un pié con dos pulgadas, y de ancho un pié con 7 pulgadas ${ }^{62}$.

$\mathrm{N}^{\circ}{ }_{23}$. Caricatura de unos Músicos. De autor desconocido. Escuela flamenca. Un organista, un tocador de violín, y dos otros cantores parece que forman un concierto tan poco harmonioso como lo es mucho el colorido y la composición de este cuadrito, que si bien es solo un bosquejo, descubre no obstante el genio particular para asunto de esta clara que distingue a los compatriotas de los Van-Ostades de los Teniers y de tantos otros. Tiene de alto un pie con ocho pulgadas, y de ancho un pie con trés pulgadas ${ }^{63}$.

$\mathrm{N}^{\circ}$ 24. Unos jugadores. Del mismo autor y estilo que el precedente. Dos Hombres del pueblo juegan a naipes encima de un tonel, y tanto esta baquica mesa, como al tener un vaso encima de ella, parece indicar que es un figon $^{64}$ el lugar de la escena. Dos otras figuras forman juego en esta sencilla pero bella composición que es, lo propio que la precedente tan solo un bosquejo. Tiene el mismo tamaño que el número anterior.

$\mathrm{N}^{\circ} 25$. Pais de la rotonda. De Salvador Rosa. Escuela Napolitana. Conforme lo hizo repetidas veces, el Artista adornó este paisaje con ruinas y restos de arquitectura antigua, copiados cual existen, pero dispuestos como mejor pareció a su gusto. Así es que sobre un fondo en que se ven peñas quebradas, montañas y una lejana población, descuella a corta distancia del primer plano el magnifico Panteon de Agrippa, llamado hoy dia la Rotonda, que se halla en efecto, casi al centro de Roma, y que á mas de ser una obra maestra del arte, es el edificio antiguo que ha quedado mas integro y conservado. Delante de este templito, y en primer termino, ha colocado el pintor las tres hermosas columnas corintias, que existen cerca del Foro Romano, restos del Templo de Júpiter Tonante, y que son tenidas cual tipo de belleza arquitectónica. A la derecha, y también en primer termi- no se eleva sobre un elegante pedestal una estatua que parece ser la del gran Pompeo, que se halla hoy dia en el Palacio Spada de Roma, y al pié de la cual los conjurados asesinos de Julio Cesar arrastraron a su victima, segun dicen, antes que expirara. Este hermosísimo cuadro está tocado con mucha maestria y soltura, la perspectiva es muy exacta, y los esbatimientos bien entendidos. Su actual posesor lo adquirio en un estado deprorable asi es que fueron necesarios algunos restauros que no salieron del todo a su gusto. Tiene de alto un pié con 5 y media pulgadas y de ancho un pié con once pulgadas ${ }^{65}$.

$\mathrm{N}^{\circ}$ 26. Pais del Jarro. De Salvador Rosa. Escuela Napolitana. A la derecha del cuadro se ven los restos del Templo de la Fortuna que se hallan en el Foro romano, y a la izquierda los del llamado Templo de Palas que se hallan en el recinto de los muros de Roma, frente del cual ha colocado el pintor al famoso Jarro antiguo, conservado en una de las salas del museo [amb llapis, una anotació sobre la línia: «vaso Borghese ó de Mèdicis»] conservado en una de las sales del museu Capitolino, y á la que da el nombre, llenando el intermedio de ambos edificios la vista del mar y un cabo monstruoso que forma una ensenada en la que un navio ingles zarpa el ancla y riende las velas, combinación del mas bello efecto, aunque tan diversa de la verdadera situación de los edificios. Este pais cual el procedente que es su compañero, es admirablemente tocado sobretodo los bajorelieves del vaso, y de las ruinas que se hallan al pié del Templo de Palas. Tiene las mismas dimensiones que el precedente.

$\mathrm{N}^{\circ}$ 27. Las Bodas de Caná. Se celebraron unas bodas en Caná de Galilea, y fue también convidado Jesús y sus discípulos a las Bodas, y llegó a faltar vino [...] y había allí seis hydrias de piedra conforme a la purificación de los judíos, y cabian en cada una dos o tres cántaros. Y Jesús les dijo: llenad las hydrias de agua. Y las llenaron hasta arriba, y Jesús les dijo: sacada hora y llevad al Maestresala. Y lo llevaron. Y luego que gustó al Maestresala el agua hecha vino, y no sabia de donde era aunque los que servían lo sabían porque habían sacado el agua. LLamo al esposos el Maestresala y le dijo: Todo hombre sirve primero el buen vino, y después el que no es tan bueno: mas tu guardaste el buen vino hasta ahora (Evangelio de Sn Juan Cap. II). La bien estudiada disposición de este cuadro, en que no se advierte la menor confusión á pesar del grande número de figures que contiene, lo vigoroso del colorido. Y la minuciosa delicadeza con que está acabado en algunas de sus partes, le dan un merito particular, y harían sospechar que fuese de origen flamenco, pero el penúltimo personaje de la derecha que lleva un turbante encarnado es casi idéntico a otra figura de un cuadro pintado según suponen por el gran Velázquez; como asi mismo el traje del cual está sentado y de espaldas en el primer plano y varios [...] tienen una semejanza notable en ambos cuadros. Advirtiendo que aquel es de asunto del todo diverso del de esta. Más quizás sea afecto de la casualidad. Este cuadrito es pintado sobre cobre, al que se ha oxidado por desgracia en algunos [...], y causado algún daño a la pintura. Tiene de alto I I pulgadas y de ancho un pie con tres pulgadas ${ }^{66}$. 
$\mathrm{N}^{0}$ 28. El Samaritano. De autor desconocido. Un hombre bajaba de Jerusalem a Jericó y dio en manos de unos ladrones los cuales le despojaron, y después de haberlo herido, le dejaron medio muerto y se fueron. Aconteció pues que pasaba por el mismo camino un sacerdote y cuando le vió pasó de largo. Y asi mismo un Levita llegando cerca de aquel lugar, y viéndole pasó también de largo. Mas un samaritano que iba su camino se llegó cerca de él, y cuando le vió se movió á compasión y acercándose le vendó las heridas echando en ellas aceite y vino, y poniéndole sobre su bestia lo llevó á una venta y tuvo cuidado de él. Parabola de Jesus en el Evangelio de Sn Juan Cap. $\mathrm{X}$. Tal es lo que representan las figuras algo mal dibujadas de este cuadrito, pero es bastante bien tocado el tronco y ramaje del árbol al pié del cual pasa la lastimosa escena. Tiene de alto siete pulgadas con 4 lineas y de ancho 9 pulgadas con 8 lineas. Y está pintado sobre cobre.

$\mathrm{N}^{0}$ 29. La Virgen con el niño Jesús. De Bartolomé Murillo. Escuela Sevillana. Aunque esta no sea por cierto una de aquellas obras del inmortal artista que se cita, hijas de su ultimo y perfeccionado estilo, no obstante el correcto dibujo, las bien entendidas posturas, la belleza y frescura de las carnes, los bien plegados ropajes, y el perfecto claro-obscuro y admirable reposo son calidades que denotan la mano maestra que suponen lo trazó, y que ya en sus primeros ensayos (que suelen llamarse su estilo naturalista) se descubria un genio. Tiene de alto I 3 pulgadas y de ancho ro pulgadas ${ }^{67}$.

$\mathrm{N}^{\mathrm{o}}$ 30. Sta. Magdalena penitente. De Fray Joaquin Juncosa, Cartujo catalan. Despues de Viladomat, pasa Juncosa por el mejor pintor que haya producido nuestra Provincia, tan poco fecunda comparativamente con otras en distinguidos artistas. Esta producción suya es admirable por la suavidad del colorido, y la viva expresion de la penitente y su graciosa posición. Al que le pareciera estraño que un cartujo haya pintado una mujer con los pechos tan al aire será del caso advertible que Juncosa fue pintor antes de entrar en la Cartuja de Valldemosa en Mallorca, de donde se escapó para volver al mundo, ó a lo menos asi se cuenta. Por consiguiente en ambas épocas pudo pintar el lienzo de este numero?, sin que haya nada que reprochar al cenobita. Este cuadro perteneció al S. Ciscar Obispo de Barcelona. Tiene de alto I pié con 5 pulgadas y media, y de ancho 4 piés con 2 pulgadas ${ }^{68}$.

$\mathrm{N}^{\circ} 3$ I. Un labrador. De Montaña, pintor catalán. La robustez del cuerpo, y el sosiego del alma, dones con que recompensa la Providencia los afanes del pobre labrador rebosan en el semblante del gañan que nos presenta este cuadro, y si bien su colorido sea harto vivo, no obstante hay mucha verdad en esta figura que seguramente seria la copia de un natural. Montaña vivía todavía a principios del presente siglo, y este cuadro perteneció á uno de sus discípulos. Tiene de alto 2 piés con 2 pulgadas, y de ancho un pié con 9 pulgadas.

$\mathrm{N}^{\circ}$ 32. San Pablo. De autor desconocido. Tiene de alto I pié con 6 pulgadas, y de ancho un pié con 2 pulgadas. [Anotació amb llapis on diu «cambiado».]

$\mathrm{N}^{\circ}$ 33. La oración en el Huerto. De Orrente. Escuela Valenciana. Jesús se fue al monte de las Olivas y les fueron siguiendo sus discípulos. Y cuando llegó al lugar les dijo: Haced oración [...] y se apartó él de ellos como un tiro de piedra, y puesto de rodillas oraba diciendo: Padre, si quieres traspasa de mí este cáliz: mas no se haga mi voluntad sino la tuya. Y le apareció un ángel del cielo que le confortaba. Y puesto en agonía oraba con mayor vehemencia [...] y como se levantó de orar, vino a sus discípulos, y los halló durmiendo de tristeza [...] y se dejó ver una quadrilla de gente, y el que era llamado Judas uno de los doce iba delante de ellos [...] San Lucas Cap. XXII. El cuadro de este número exacta representación de tan patético lance es admirable tanto por su composición como por el diseño, colorido y expresión. La disposición de la escena no puede ser mejor entendida y los varios y acertados accidentes de luz, tanto la que arrojó el enviado celeste, como la que resplandece de la luna contra las opacas nubes que la velan, produce un efecto maravilloso. Mas el contraste de lo gracioso y aéreo del paraninfo, con la abatida resignación del Divino Redentor, y el sensual descanso de los discípulos, da á esta obra un mérito excesivo. La lejana vista de los que vienen a prender a Jesús, conducidos por Judas, es así mismo muy bien tocada. Este cuadro está pintado sobre madera y tiene de alto un pié con 5 pulgadas y media, y ancho un pié con una pulgada ${ }^{69}$.

$\mathrm{N}^{\mathrm{o}}$ 34. Pais con un puente de dos arcos. De S. Maurell [?]. Escuela Francesa. Por debajo las arcadas de un grande y antiguo Puente que ocupa casi todo el primer termino se descubren unas hermosas lejanías cubiertas de colinas cuyo pié bañan las aguas de un caudaloso rio. Un esquife con dos barqueros, que parece van á atravesarlo, y unas mujeres que estan lavando, miman esta composición, ya notable por los bonitos efectos de luz que proporciona el mismo puente. Este cuadro lleva la firma de su autor, y tiene de alto un pié con 5 pulgadas, $\mathrm{y}$ de ancho 2 piés con una pulgada.

$\mathrm{N}^{\mathrm{o}}$ 35. Pais con un hombre á caballo y ganado. Este paisaje figura estar iluminado por la luz de la luna, cuando en una noche de verano sale rojiza, y esclarece el horizonte cual si fuera la venida del sol. Lo opaco del celage, las puntas blanqueadas de las ramas, y sobre todo, las largas sombras y tan marcadas de las bestias proyectadas sobre el suelo, lo manifiestan claramente. Por lo demás el ganado está bien agrupado, y bien trazada la figura del conductor. Tiene las mismas dimensiones que el precedente y quizás sea del mismo autor.

$N^{o}$ 36. Jesus con la Cruz á cuestas. De autor y Escuela desconocida. Este precioso cuadrito, á mas del mérito de su correcto dibujo, sobre sale particularmente por el tono de su colorido, que es del todo harmonioso, y contribuye mucho en sostenerlo tal, el vestido blanco con que va cubierto Jesus, signo de la locura con que la filosofía de Herodes atacaba la Divina Sabiduria. El sayón de la izquierda está rebajado con mucho arte. Ha habido quien ha estimado esta composición como un Boceto de Ribera. Tiene de alto ro pulgadas con 4 lineas, y de ancho 8 pulgadas con 6 lineas.

$\mathrm{N}^{\mathrm{o}}$ 37. Pais. De autor desconocido. Escuela francesa. Una frondosa arboleda llena de aire y de naturalidad, al 
través de la cual se descubre un vaporoso y caliente celage, forman el merito de este lienzo. Mas, como sucede amenudo, el excelente pintor de paisajes no lo es de figuras, pues las de este en particular la de la mujer, desluce mas bien que adorna el cuadro. El inmortal Claudio de Lorena hacia pintar por sus amigos las figuras que quería poner en sus paises. Tiene de alto 2 piés con 5 pulgadas, y de ancho 2 piés con 7 pulgadas. [Anotació amb llapis on diu «cambiado».]

$\mathrm{N}^{\circ}$ 38. Pais. De autor desconocido. Escuela francesa. Este paisaje admirable por el vaporoso ambiente que le cubre ofrece unas rocas coronadas de bellísimo ramaje, y cuyo pié bañan las transparentes aguas de un rio sobre el cual hay un rustico puente que une las dos orillas, formando al [?] el primer plano; mientras que al fondo se descubre la lejana corriente, y una elevada montaña á cuya cima se apercibe a penas un vasto edificio; mas lejos y al pié de la montaña se ve una población. Esta pintura es del mismo autor que la del numero precedente, y hay indicios que los dos formaron un mismo cuadro, pero que después fueron cortados y separados en dos. Tiene las mismas dimensiones que el precedente.

$\mathrm{N}^{\circ}$ 39. Una Batalla. De Jacques Courtois, llamado el Bourguignon. Escuela Francesa. Este cuadro presenta un terrible choque de caballería contra peones, y el traje y las armas de estos indican ser arquebuceros del tiempo de Luis XII, época en que á corta diferencia vivía el autor. Hay mucho fuego en la composición de este cuadrito aunque es bastante despachado, como suelen serlo los de esta clase. Ha sido forrado. Tiene de alto un pié con 7 pulgadas, y de ancho dos piés con una pulgada ${ }^{70}$.

$\mathrm{N}^{\circ}{ }_{40}$. Bautismo de Jesus. De Jacopo de Ponte (El Bassano). Escuela Veneta. Entonces vino Jesus de la Galilea al Jordan a Juan para ser bautizado por él. Mas Juan se lo estorbaba, diciendo: ¿Yo debo ser bautizado por ti, y tu vienes a mi? Y respondiendo Jesus le dijo: Dexa ahora, porque asi nos conviene cumplir toda justicia. Entonces le dexó, y después que Jesus fué bautizado, salió luego del agua. Y he aquí se le abrieron los cielos, y vió al Espiritu de Dios, que descendia como paloma, y que venia sobre él. Y he aquí una voz de los Cielos que decía: Este es mi hijo el amado en quien me ha complacido. San Mateo Cap. III. Asunto de la bellísima composición de este numero, que tal vez es de lo mejor que haya procedido el pincel de su afamado autor. En efecto junto á una disposición la mas feliz, hay una corrección de dibujo admirable. La bellísima morbidez de las carnes del Hombre Dios, el perfecto estudio en [?] de todas las figuras, y sobre todo el singular relieve que se observa en la que está a la derecha y vuelta de espaldas, son distinguidas perfecciones de este cuadro, en todas sus partes y hasta en sus accesorios excelentes. El artista no ha desmentido aquí, por cierto, el alto renombre de buenos coloristas que ha tenido la Escuela Veneta. Tiene de alto un pié con ocho pulgadas, y de ancho 2 piés con una pulgada ${ }^{71}$.

$\mathrm{N}^{\circ}$ 4I. El Angel de la Guarda. De autor desconocido. Está pintada sobre madera y tiene de alto I 3 pulgadas y de ancho 8 con 9 lineas ${ }^{72}$. [Anotació amb llapis on diu «cambiado».]
$\mathrm{N}^{\circ}$ 42. Virgen con el niño de la Palomita. De Ant ${ }^{\circ}$ Alegri, llamado el Correggio. Escuela Lombarda [ratllat amb llapis «De Ant ${ }^{\circ}$ Alegri, llamado el Correggio»]. Esta hermosa Pintura sobre tabla, obra al parecer del inmortal jefe de la escuela Lombarda, pues que tal lo atestigua el gracioso dibujo, la mágica disposición, lo palpitante de las carnes, las transparentes velaturas, los elegantes ropajes, y finalmente una porción de belleza dificil de describir; esta tabla digo, sirvió durante mucho tiempo para cerrar una ventana, y mas que las inclemencias del tiempo lo deterioró una mano atrevida que queriendo sin duda limpiarlo, lo restragó al punto de dejarlo en cierto parage casi sin color. Afortunadamente que su actual poseedor lo confió para su restauración al distinguido artista de Valencia Dn. José Viló que desempeñó tan difícil encargo con bastante acierto. Se ha dado el nombre del Niño de la palomita á ese cuadro para llamar la atención sobre el Jesus que es admirablemente pintado, y sobre todo por la feliz idea de colocar en sus manos una Palomita y una Cruz, símbolos de la inocencia y del castigo. Tiene de alto un pié con ro pulgadas y de ancho un pié con 4 y media pulgadas, aunque ahora figura ser circular, y de un pié con I i pulgadas de diámetro.

$\mathrm{N}^{\circ}$ 43. Jesus clavado á la Cruz. De autor desconocido. Escuela Valenciana. Este cuadro es solo un fragmento de un lienzo mayor, y de extensa composición destrozada por la barbara mano de la revolución. Aunque su colorido es poco brillante, el dibujo es bello y la expresión tierna y perfecta. Tiene de alto un pié y de ancho un pié con 2 pulgadas y media. [Anotació amb llapis on diu «cambiado».]

$\mathrm{N}^{\circ}$ 44. Retrato antiguo de mujer. De autor desconocido. Está pintado sobre cobre y tiene algunos accesorios bastante bien tocados. Tiene de alto I 3 pulgadas y de ancho Io pulgadas ${ }^{73}$.

$\mathrm{N}^{\circ} 45$. Virgen con el niño. De autor desconocido y muy antiguo. Si las figuras con envarados y casi descarnados miembros, la simetría en la posición de estos, lo opaco del colorido, la falta casi total de perspectiva, y las aureolas y adornos dorados son señales que caracterizan y distinguen las obras de los primeros pintores al oleo del siglo XV, no se podrá negar que lo sea la que lleva este número, al propio tiempo que participa de las ventajas de un correctísimo dibujo, y de la mucha expresion con que solian sobresalir los artistas de aquellos tiempos. El niño ha sido estropeado por algún ignorante queriéndolo restaurar. Tiene de alto 9 pulgadas con 8 lineas, y de ancho 7 pulgadas con 4 lineas. Esta pintado sobre una gruesa plancha de cobre. [Anotació amb llapis on diu «cambiado».]

$\mathrm{N}^{\circ}$ 46. La aparición de Jesus a la Magdalena. De Mola. Escuela Lombarda. Y vino Maria Magdalena de mañana al sepulcro [...] y Pedro y aquel otro discípulo á quien amaba Jesús [...] fueron también y vieron quitada la losa $[\ldots]$ y entraron en el sepulcro $[. .$.$] y solo vieron$ los lienzos y el sudario [...] y se volvieron otra vez los discípulos á su casa. Pero Maria estaba fuera llorando junto al sepulcro [...] y se volvió a mirar atrás, y vió a Jesus que estaba en pié; mas no sabia que era Jesus. Jesus le dijo: ¿Muger porque lloras? ¿A quien buscas? 


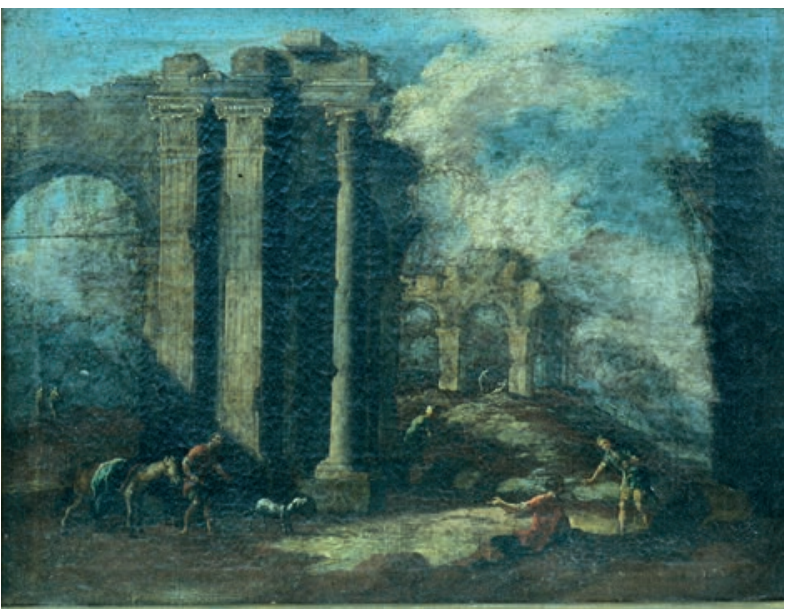

Figura 11.

Anònim napolità, Paisatge amb rü̈nes, Masia d'en Cabanyes. Fotografia: Carles Aymerich, CRBMG.

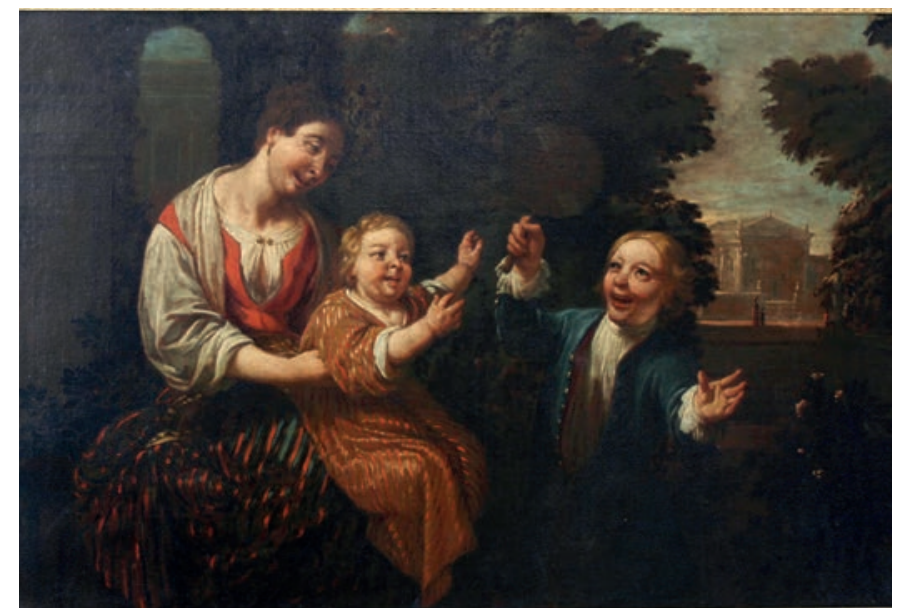

Figura 12.

Antoni Viladomat, Dona amb dos infants jugant al jardí, col-lecció Neus de Cabanyes. Fotografia: autor.
Ella creyendo que era el hortelano le dijo: Señor, si tu lo has llevado de aquí dime en donde lo has puesto, y yo lo llevaré (y volvió otra vez su vista hacia el sepulcro) [...] y Jesus le dice: Maria. Vuelta ella le dice: Rabboni, que quiere decir Maestro. Jesus le dice: no me toques, porque aun no he subido a mi Padre: mas ve á mis hermanos y diles: subo á mi Padre y vuestro Padre á mi Dios y vuestro Dios. Evangelio de San Juan. Cap. XX. Este tierno paso es el que ha querido representar en el presente numero el distinguido discípulo del Albano, y á imitación de lo que hacia con tan merecido aplauso su ilustre maestro ha unido aquí la pintura de figuras á la del paisaje. El Jesus es admirable por su dibujo, bella postura y colorido. Maria Magdalena lo es igualmente por la mucha expresión, y aunque á primera vista aparezcan sus manos harto grandes y abiertas, si se atiende al estado de pasmo en que debemos suponerla, se conocera que no es defecto, sino pura verdad. El pais es sobremanera frondoso, variado y bello, aunque los arboles carecen de aire y ligereza, mas el celage es hermosísimo. Tiene de alto un pié con i i pulgadas, y de ancho dos piés con 7 y media pulgadas.

$\mathrm{N}^{\circ}$ 47. Pais con ruinas [figura I I]. De Salvator Rosa. Escuela Napolitana. Aunque este cuadrito sea un mero bosquejo, pues en la mayor parte de él se aperciba todavía la preparación del lienzo, sin embargo descubre la mano maestra que lo ha pintado, y aquel gusto particular en adornar sus composiciones de restos de antigua arquitectura. Tiene de alto un pié con 4 pulgadas y de ancho un pié con 9 pulgadas ${ }^{74}$.

$\mathrm{N}^{\mathrm{o}}$ 48. Otro Pais con Ruinas. De Salvatore Rosa. Escuela Napolitana. Este pais es compañero del precedente con todos sus defectos y meritos. Tiene asimismo iguales dimensiones ${ }^{75}$.

$\mathrm{N}^{\circ}$ 49. Unos pescadores. De Viladomat. Puesta ya fuera del agua su barquilla, unos pescadores se ocupan en recoger la abundante pesca que han hecho. Dos de ellos se hallan todavía dentro de la canoa al paso que otro, sentado á su borde quita los últimos pescadillos cogidos aun á las redes, ya acaba de llenar una canasta, teniendo al suelo otra ya llena, y otra que vertida presenta varios grandes pescados que contenia. A lo lejos se descubre un muelle adornado de grandes y suntuosos edificios, y unas lanchas que cruzan el puerto. Aunque este lienzo se resiente de la tan común dureza del autor no obstante está todo presentado con tanta naturalidad y maestria que recompensa con usura aquel defecto. Los pescados y mariscos estan despachados con mucho gusto y acierto. Este cuadro lo heredó su actual posesor de su muy amado tio Dn. Juan Bta. Ballester de Carro, quien lo tenia junto con los tres siguientes. Tiene de alto 3 piés con 2 pulgadas, y de ancho 5 piés con 6 pulgadas $^{76}$.

$\mathrm{N}^{\circ}$ 50. Muger con un chiquillo de teta al regazo y jugando con otro niño [figura I2]. De Viladomat. Se percibe tan de luego en las fisonomías de la tres figuras que componen el primer plano de este cuadro un aire de familia, que no cabe duda, que al pintar nos quiso representar la tierna escena de una madre, que se complace en ver los alegres é inocentes juegos de sus hijos. Así es que empleando toda la naturalidad y delicadeza de que era susceptible su admirable pincel, el insigne pintor catalán consignó en este lienzo una de sus mas bellas obras. La composicion no puede ser mejor entendida, el dibujo mas gracioso, la expresion mas viva. El paisaje ofrece un ameno jardín y una lejana y magnifica Quinta. Este cuadro lo compró su actual poseedor á la Sra. de Carro, con cuyo producto mandó pintar su cava y hacer otras mejoras. Tiene de alto dos piés con nueve pulgadas, y de ancho cuatro piés con siete pulgadas.

$\mathrm{N}^{\mathrm{j}}$ 5 I. Caballero tocando la guitarra y dos señoras. De Viladomat. Si la precedente composición (compañera de la presente, y con la que hace juego) manifiesta ser una escena de familia, la de este numero indica ser un tierno galanteo; pues que tal lo atestigua la mirada del amante, y la fingida indiferencia de la querida. Por lo demás este cuadro tiene las bellezas y defectos tan 
peculiares á las obras de Viladomat, distinguiéndose por un raro efecto de luz que solo ilumina parte de la cara del hombre dejando casi del todo sombreadas las figuras de las dos mugeres. Este hermoso cuadro lo regaló á su actual posesor su muy venerado tio Dn. Jose Maria Ballester de Carro. Es Prior Presidente del Monasterio de Santas Creus. Tiene el mismo tamaño que el precedente del cual se ha dicho ya que era compañero.

$\mathrm{N}^{\circ}$ 52. Señora con un perrillo de falda y una niña. De Viladomat. El asunto de este lienzo, sino tan tierno como el del numero 50, es á lo menos tan natural. Una niña de pocos años teniendo en una mano muñeca, quiere con la otra coger el abanico de una señora, que según el semblante será una tia suya sin hijos, haciéndolo sospechar asi un perrito faldero que tiene á su regazo, el cual lame el brazo de la niña. Aunque este cuadro parece ser por el mismo gusto que los dos precedentes, sin embargo no llega de mucho al merito de ellos, y está muy despastado y algo deteriorado. Tiene el mismo tamaño que el numero 49. Este cuadro cayó en suerte a mi Sra. Tia $\mathrm{D}^{\mathrm{a}}$ Antonia Garesa de Tarragona, y á pesar que tácitamente lo haya cedido á su actual posesor, como no es formalmente no lo nota aquí como propiedad cierta.

$\mathrm{N}^{\circ}$ 53. Pais. De Dn. Joaquin de Cabanyes. Facil es percibir a primera vista los inmensos progresos que ha hecho el pintor de este cuadro y de los tres siguientes comparándolos con los números 8 y 9 del presente Catalogo. Mas aquellos fueron sus primicias y estos son frutos de mas asiduos estudios dirigidos por el Sr. Villamil, uno de los primeros profesores de la Corte. Son datados de Segovia a mediados del año i 842 . El del presente numero sobresale por la frescura de la arboleda, por los delicados lejos, seguridad de toques, transparencia del agua, hermoso celage y tono harmonioso. Tiene de alto I pulgadas y media, y de ancho I pié con una pulgada ${ }^{77}$.

$\mathrm{N}^{\circ}$ 54. Pais con un camino con casas. De Dn. Joaquin de Cabanyes. El tono caliente de este paisaje, los bien estudiados efectos de luz, lo bien tocado de todo el primer termino dan un particular merito á esta pintura pero sobre todo las varias figuritas que contiene le miman de un modo admirable. Tiene las mismas dimensiones que el precedente $\mathrm{e}^{78}$.

$\mathrm{N}^{\circ} 55$. Vista de una parte de la Alhambra de Granada. De Dn. Joaquin de Cabanyes. Hermosisimo es este cuadrito por la delicadeza de sus tintas, lo bien estudiado de la perspectiva, el admirable contraste de sus prolongadas sombras con sus claros y el tono singular de todo el conjunto que da una fisonomía fantástica al edificio, tan análogo a los de su clase. Está pintado sobre hoja de lata. Tiene de alto ro y media pulgada, y de ancho 7 pulgadas con $\mathrm{i} 0$ lineas ${ }^{79}$.

$\mathrm{N}^{\circ}$ 56. Pais del Puente de un arco. De Dn. Joaquin de Cabanyes. A pesar de la extrema sencillez de esta composición es al propio tiempo tan felizmente hallada, que con placer descansa la vista sobre ella; y tanto lo bien tocado del puente y peñasco sobre que se apoya, como los rusticos edificios que se ven por debajo su arcada, formando un hermoso borde á las transparentes aguas, lo hermosean en extremo. Es una vista tomada en las

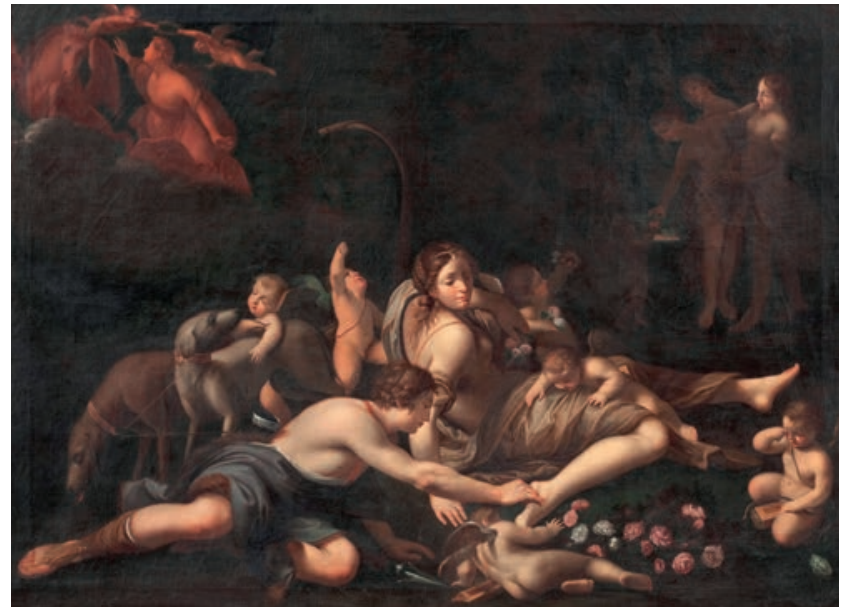

Figura 13.

Anònim d'escola romana o bolonyesa (còpia de Marco Antonio Franceschini), Adonis treu una estella del taló de Venus, Masia d'en Cabanyes. Fotografia: Carles Aymerich, CRBMG.

cercanías de Segovia. Tiene de alto y ancho lo mismo que el precedente y es asimismo pintado sobre hoja de lata ${ }^{80}$.

$\mathrm{N}^{\circ}$ 57. Coloracion de las Rosas [figura I 3 ]. Copia del Albano. Escuela Lombarda. Cuenta la mitología que yendo un dia la diosa Venus á la caza con su querido Adonis, se lastimó el pié con las espinas que pisó de unos rosales, que hasta entonces habían dado solamente flores blancas, y que teñidas estas con la sangre que brotó dela herida, cambiose su albo color en el purpurino que tienen ahora. Si Albano no hubiese merecido por una infinidad de obras admirables producciones el ser llamado el pintor de las Gracias á buen seguro que se procurara tal renombre esta sola composición, pues no es dable imaginar una escena presentada de un modo mas bello y gracioso. La habilidad del claro obscuro es aquí admirable, y no nos atrevemos á enumerar las otras bellísimas circunstancias, pues son sin numero y todas muy relevantes. El original de este cuadro se halla en la Lonja de Barcelona de tamaño doble del de esta copia, la que tanto por la fidelidad del diseño, como por la delicadeza y brillo del colorido es digna de atención. Tiene de alto 3 piés con 2 pulgadas; $y$ de ancho 4 piés con 4 pulgadas ${ }^{81}$.

$\mathrm{N}^{\circ}$ 58. Muerte de Meleagro. De Domingo Lampieri llamado Dominiquino [el nom està ratllat]. Escuela Bolonesa. Para vengar la muerte de sus hermanos, Athea cruda madre de Meleagro, repone al fuego aquel tizon fatal de cuya duración, (según pronóstico de las Parcas) dependía la vida de su hijo; y en el propio instante resiente el desdichado un ardor que consume sus entrañas, y que acabará con la vida luego que queda reducido a cenizas aquel madero. Famoso ya el Dominiquino por la grande expresividad que sabía dar á sus figuras, no se desmiente aquí pues que muy admirable es la expresión del padecimiento de la victima; admirable la expresión de su tierna esposa Atalanta, que bien caro paga ahora el triunfo que le procuró la muerte del Javali de Calydonia; admirable es el bien plegado manto de la mujer que esta mas á a derecha; y admirable es todavia el efecto de 


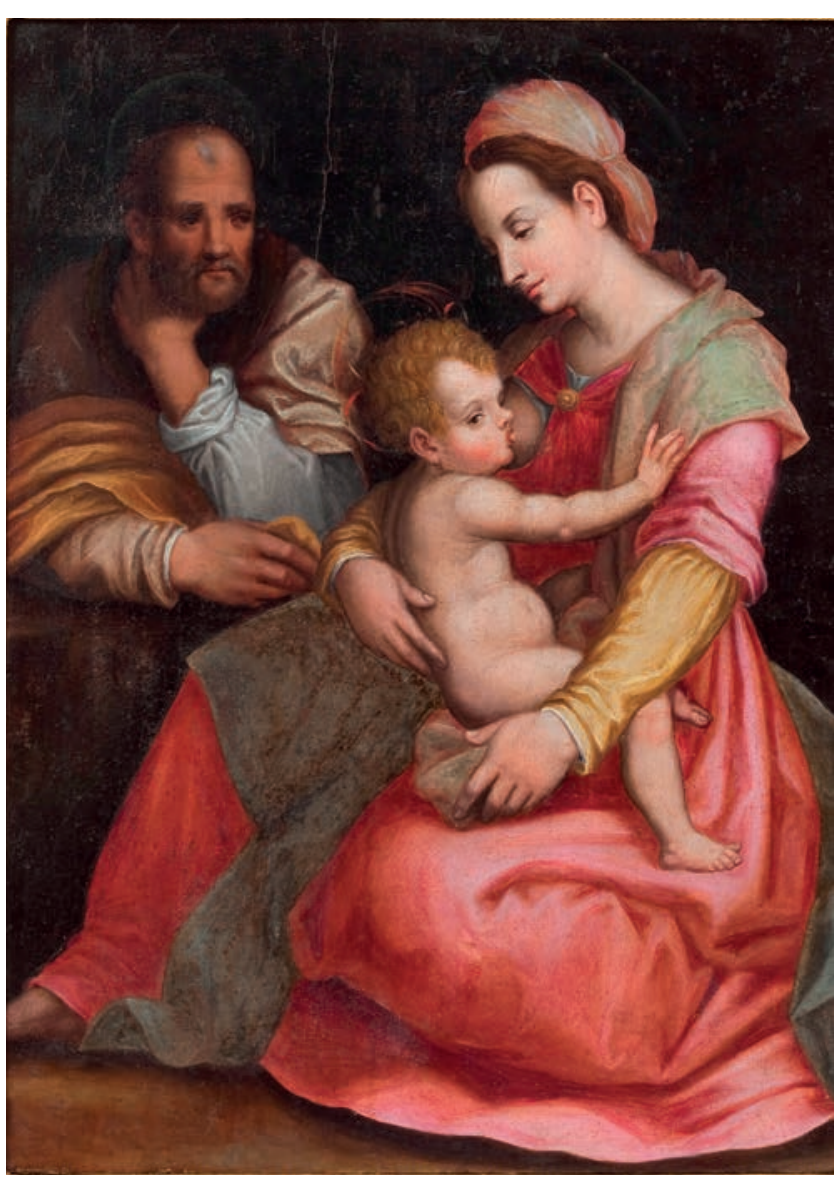

Figura 14.

Anònim (còpia d'Andrea del Sarto), Sagrada Familia, Masia d'en Cabanyes. Fotografia: Carles Aymerich, CRBMG.

luz con que el hábil artista ha sabido hacer resaltar estos personajes del fondo obscuro y análogo a la fúnebre escena que este lienzo nos representa. Este cuadro y los tres siguientes son forrados, y parece que fueron de forma ovalada, según lo indican las visibles correcciones de sus angulos. Hay quien los ha juzgado obra del Poussin. Tienen de alto 3 piés con 3 pulgadas, y de ancho 4 piés con 5 pulgadas ${ }^{82}$.

$\mathrm{N}^{0}$ 59. Diana descubriendo la preñez de Calisto. De Domingo Lampieri llamado Dominiquino [el nom està ratllat]. Escuela Boloñesa. Este asunto tratado ya por obras de los mas famosos pintores, lo ha sido aquí por el Dominiquino con un acierto el mas feliz; pues la naturalidad de los ademanes, y la particular expresión de cada una de las figuras (parte en que tanto excelia el autor) la morbidez de las carnes, y lo bien entendido de la disposición, junto con la belleza del paisaje que forma el fondo del cuadro, le hacen sin contradicción de un merito rarísimo. Tiene el mismo tamaño que el precedente ${ }^{83}$.

$N^{\circ}$ 6o. Rapto de Europa. De Domingo Lampieri llamado Dominiquino [el nom està ratllat]. Escuela Bolonesa. Transformado Jupiter en Toro (á tanta miseria obliga el amor; á lo menos asi lo contaban del tonante Numen) logró con su blancura sus hermosas formas, y su mansedumbre llamar la atención de la inocente
Europa, que con sus compañeras se divertia cogiendo flores á la orilla del mar; y formando de ellas una guirnalda coronaba al fingido animal, que se postraba como para recibir aquel obsequio. La incauta Joven se sienta entonces sobre su lomo, y rie al ver la suavidad con que anda su singular montura, sin advertir que este se dirigía hacia el mar, y que se metia dentro de sus aguas; mas cuando ve que la olas le mojan ya los piés su alegría se convierte en pavor, y cogida de las astas del toro por no caerse, dirige sus miradas y sus lamentos á sus compañeras, que sorprendidas igualmente, no pueden ya desde la orilla, prestarle el menor auxilio. Este es el momento de tan singular historia, que nos ha representado el pintor en este lienzo, hermoso por demás. El grupo de las compañeras de Europa es interesantísimo, y lleno de expresión y movimiento; y cuando la viveza del bruto no indicase ya misterio, harto lo declararía el gracioso amorcillo que sigen por los aires al que va mar á dentro. El contraste del tostado Triton con las delicadas carnes de las ninfas aumenta el interés de este cuadro lo propio que el hermoso paisage y cielo. Tiene el mismo tamaño que los dos precedentes ${ }^{84}$.

No 6r. Unas Musas. Composicion alegorica. De Domingo Lampieri llamado Dominiquino [el nom està ratllat]. Escuela Bolonesa. Cual suele suceder con muchas alegorías cuya explicación no siempre es fácil, la que nos presenta este lienzo tiene á lo menos para nosotros su poquillo de obscuridad. Si la ninfa que vemos al centro de la escena es la Musa Caliope, como parece indicarlo el clarín que lleva en su mano derecha; como carece de sus otros atributos que podrían manifestarla mas $\mathrm{Y}_{\check{C}} \mathrm{Cual}$ es la otra ninfa que esta abrazada con ella, tan estrechamente que parece besarla, al paso que tiene á sus piés mascaras, instrumentos y papeles de música, y otros objetos? Seguramente que no será Talia ni Terpsicoris, musas de la comedia y de la danza, pues en lugar de llevar sus atributos, parece que los pisotea y desprecia confundiéndolos con los juegos viles cual es la baraja que entre ellos se descubre. ¿Y la otra ninfa mas á la derecha quien puede ser? Ninguna señal ni atributo nos lo indica, y solo si la vemos abrazada con otra que por tener un relox de arena á la mano quizas nos indica representar una de las Horas, ó tal vez el tiempo. En el fondo vemos á otra ninfa que está escuchando atentamente lo que dicen estas dos ultimas para trasladarlo al papel que está escribiendo. En el mismo fondo a la izquierda se descubre una especie de monumento al pié del cual está sentado, ó mas bien medio tendido uno, al parecer, como filósofo, con barba cana, y casi desnudo que dirige sus miradas á otros dos que se hallan de pié delante de él., el uno con túnica y trage que parece romano, el otro con manto griego, que le cubre desde la cabeza hasta los piés. ¿Nos presentarían á caso estos tres personajes á Hesiodo, Homero y Virgilio y el grupo de Ninfas á la sublime Poesia épica? Sea lo que fuere de ello, lo cierto es que esta composición es hermosísima en si, tanto por lo gracioso y bello de los grupos como por el correcto diseño, el riguroso colorido, lo delicado de las carnes, los bien plegados ropajes, y finalmente el hábil contraste de los apartados y bien re- 
bajados filósofos ó sean poetas. Tiene el mismo tamaño que los tres anteriores ${ }^{85}$.

$\mathrm{N}^{\circ}$ 62. Virgen dando de mamar al niño Jesus, y Sn. José [figura I4]. De Andrés Vennuchi llamado Andrea del Sarto. Escuela Florentina. Agradable es por demás el reposo que siente la vista al contemplar esta hermosa composición de Andrés del Sarto, ya tan famoso por su acierto en pintar sacras Familias. Ni ha desmentido aquí el pintor su renombre de buen colorista, pues en esta composición es brillante, y los rebajados de la figura de San José son admirables. Es fácil conocer que este cuadro ha sufrido algunos repintes ó restauraciones, y es fuerza asimismo convenir que han sido muy poco acertados. Está pintado sobre madera, y tiene de alto 2 piés con una pulgada, y de ancho un pié con 6 y media pulgadas $^{86}$.

$\mathrm{N}^{\circ}$ 63. San José con el niño Jesus. Está firmado Cristo Glusianus. 1726. Tal es el nombre que lleva este cuadro pintado en una como tarjeta á su respaldo, nombre que nos es del todo desconocido. Sin embargo la obra es bella. La cabeza del santo es hermosísima, y muy expresiva, y su tono tostado y arrugado cutis contrasta admirablemente con las blancas y mórbidas carnes del niño Dios. Tiene de alto 2 piés con 8 pulgadas, y de ancho 2 piés con una pulgada.

No 64. Santa Cecilia. De autor desconocido. Escuela italiana. Sea cual fuere el autor de este cuadro, y la escuela de Italia á que pueda pertenecer, (pareciendo indudable que nació en aquella nación) no tiene duda que es de un raro mérito, y que la suavidad con que está pintado lo distinguen de un modo particular. Tiene de alto 3 piés, y de ancho dos piés con 5 pulgadas.

No 65. Sacra Familia del Xilguero. De Andrés del Verrochio [ratllat amb llapis] Escuela Florentina. Sabido es que el Verrochio (nacido en I 432 y maestro que fue del inmortal Leonardo da Vinci, pero que quedó muy atrás de su discípulo) se le tilda de dureza de pincel, y de muy mal colorista, pero al propio tiempo es muy aplaudido. Su esmerado dibujo y lo gracioso de los aires de cabeza de sus figuras, ventajas y defectos que se hallan acumulados en el presente cuadro. Es de creer que la figura de hombre que se ve á la derecha representa San José, aunque no lleva el trage con que comúnmente suele pintarse; pero es difícil adivinar cual será la joven y bella mujer que se halla á la izquierda. Nosotros sin embargo le hemos dado el nombre de Sacra familia, y la hemos distinguido con la particularidad del Xilguerillo que el niño lleva á la mano. Este cuadro está pintado sobre tabla, y tiene de alto dos piés con una pulgada, y de ancho tres piés.

$N^{\circ}$ 66. Sacra Familia. De Simon Vouet. Escuela Francesa. Simon Vouet es mirado como el fundador de la Escuela Francesa, y ha dejado un número inmenso de obras, lo que perjudica mucho á su perfeccion; asi es que la del presente numero se resiente algún tanto de esta precipitación. A mas, sea efecto del tiempo, ó defecto de buen colorido, es de sentir que está tan obscurecido, pues la figura de la Virgen es muy expresiva, y pintada en mucha suavidad, y la de San José rebajada con mucho arte. Una cosa rara en la presente composicion es que en un campo tan dilatado, haya el autor arrinconado todas las figuras á la una mitad del cuadro, dejándola otra mitad despoblada, ofreciendo solo un paisaje que á la verdad no es muy interesante. Tiene de alto 3 piés con 6 pulgadas, y de ancho 5 piés con 3 pulgadas.

No 67. Pais de la Pirámide. De Salvator Rosa. Escuela Napolitana. El estilo, el gusto, el colorido, el toque de este cuadro, identicos a los de los números 25 y 26 de esta colección, lo propio, que la semejanza del asunto (aunque llegados á las manos de su actual poseedor por muy distintas vías) descubren al hábil y laborioso artista que los hizo. Mas no recordamos haber visto en Roma, ni en ninguna otra parte las magnificas Ruinas de orden dórico que se ven aquí en primer plano, por lo que sospechamos que son de invención del autor, y no copias exactas como lo son las de los precitados números. No obstante podría darse que la Pirámide que hay en segundo plano fuese la de Cayo Cestio que se halla fuera de la Puerta Trigemina hoy dia Puerta de San Pablo de dicha Metropoli. Esta pirámide figura aquí estar colocada á la orilla de un lago ó Badia, y á lo lejos se ven unas montañas. Las figuras mas abultadas parecen ser unos mendigos que descansan de las fatigas del camino, y á la orilla del agua unos pescadores sacan una red. Esta perspectiva está perfectamente aguantada y los esbatimentos artísticamente bien entendidos. Tiene de alto 2 piés, y de ancho 2 piés con 4 pulgadas.

$\mathrm{N}^{\circ}$ 68. Pais en Ruinas. De Salvator Rosa. Escuela Napolitana. Este lienzo es en un todo compañero del anterior. El pintor ha puesto á la derecha y en primer plano las ruinas de un templo ó arco dórico, y en plano mas apartado, y a la izquierda los restos de otro antiguo edificio. Lo propio que en el número precedente no sabemos no sabemos de donde el Pintor sacó estas perspectivas, que pueden ser también obra de su imaginación, y las separa con un riachuelo en que flota una falúa con tres marineros, desembocando este rio en un lago ó Badia donde se ve á otro buque á la vela. Mas allá hay unos montes. Magnificos por demas son edificios ruinosos que adornan este cuadro, y tocados con una franqueza y maestria admirables. Es del mismo tamaño que el precedente.

$\mathrm{N}^{\circ}$ 69. La Hija de Herodias con la cabeza de Sn. Juan Bautista.Deautordesconocido.Escuela Romana. Herodes Tetrarca de Galilea vivíailegítimamente con Herodias mujer de su hermano Filipo, y Juan le decía: No te es lícito. Por lo que ella quería hacerle matar; pero Herodes sabiendo que Juan era un hombre justo, le temia. Y habiendo llegado un dia en que el Tetrarca celebraba un convite con todo lo principal de su corte, entró á bailar la hija de la misma Herodias, y agradó tanto á todos, que le dijo el rey: Pideme lo que quieras y te lo daré, aunque sea la mitad de mi reino. Ella habiendo salido, preguntó á su madre ¿Qué le pediré? Y ella le dixó: $\mathrm{La}$ cabeza de Juan Bautista. Y habiendo entrado luego con mucha prisa al rey, pidió diciendo: Quiero que me des al instante en un plato la cabeza de Juan Bautista. Y el rey se entristeció. Mas por causa del juramento y de los 


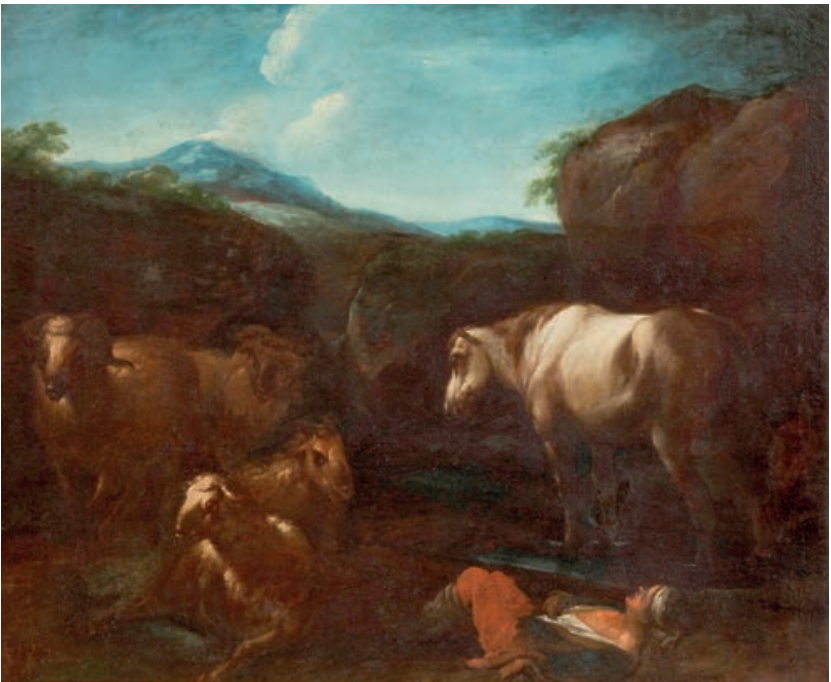

Figura 15.

Anònim flamenc o napolità, Paisatge amb cavall, Masia d'en Cabanyes. Fotografia: Carles Aymerich, CRBMG.

que estaban con él en la mesa no quiso disgustarla, antes enviando un alabardero, este degolló á Juan, y llevó la cabeza en un plato y la dio á la muchacha, y la muchacha la dio a su madre. Evangelio de San Marcos. Cap. VI. El ultimo paso de esta horrenda historia es el que representa el cuadro de este numero, y fuerza en confesar de que el artista lo ha desempeñado con particular acierto. En efecto al través de las infantiles y agraciadas facciones de la niña, se descubre ya la complice de la pérfida é incestuosa madre, y al apartar aquella los ojos del tristisimo presente, más que la debida composición, muestra mas bien hastio y desprecio. Es admirable por demás el bello y correcto dibujo de esta figura, y su extrema expresión y hasta el tono tostado del colorido, ya peculiar á la Escuela de la cual supusieron esta pintura, parece que aquí es analogo á una hija de un clima ardiente. El escorzo de la cabeza del Bautista es asimismo perfecto, y aquellos labios santos que en el desierto aclamaban penitencia, aunque cardenosos ahora por el yelo de la muerte, parecen que claman todavía dentro de los corazones esclavos de los vicios. No es licito! [...]. Tiene de alto tres piés con 8 pulgadas, y de ancho 3 piés con media pulgada ${ }^{87}$.

$\mathrm{N}^{\circ}$ 70. Pais del Novillo. De autor desconocido. Escuela italiana. En un fragoso recinto, rodeado de peñas y de ramaje, descansa tendido sobre el suelo una porción de ganado lanar, y allí junto hay un Torillo en pié. Á la derecha y en primer termino, vence unos pastores que al parecer hablan de sus reses, señalándolas uno de ellos con el brazo y mano tendida. Por un claro que hacen las peñas y la maleza, se descubre un rio, sobre el cual hay un puente, y al horizonte unos lejanos montes. Tal es la belleza de esta pintura, y tan perfecta la execucion de los animales, sobre todo del toro, que podría parangonarse con las famosas producciones de Poter y de Snyders; pero parece indudable que esta es hija de Italia, y por mas que algunos le hayan sospechado de Salvator Rosa, otros duchos inteligentes le otorgan un mas acendrado merito. Tiene de alto dos piés con 8 pulgadas, y de ancho tres piés con dos pulgadas ${ }^{88}$.

$\mathrm{N}^{\circ}$ 7 I. Pais del Caballo [figura I 5]. Del mismo autor que el precedente. A orilla de un arroyuelo que baña el pié de unos peñascos descansan, como satisfechos ya de pasto unos carneros, y en primer termino y á la derecha se ve asimismo á su pastor recrearse con la frescura del agua en la que tiene metido ambas manos. Unos montes cierran el horizonte. Este lienzo es compañero del precedente, y participa de su extremada belleza y merito. El caballo en particular está muy bien pintado, y todos los demás animales rebosan asimismo de naturalidad. El paisaje está despachado con seguridad y franqueza, y solo es de sentir que con el transcurso del tiempo se haya obscurecido bastante el colorido privándonos distinguir muchos bellísimos accesorios de que rastros todavía. Tiene el mismo tamaño que el precedente ${ }^{89}$.

$\mathrm{N}^{\mathrm{o}}$ 72. Venus abrazada con su hijo. De Antonio Alegri [ratllat amb llapis i escrit «Annibal Carraccio»], llamado el Corregio. Escuela Lombarda. Sentada graciosamente, y algo reclinada sobre unas rocas se ve a la Diosa de Pafos abrazando á su hijo, que se apoya sobre la rodilla derecha y la puntita del pié izquierdo para poder arrimar mas su boca á la de su amorosa madre. La pureza del diseño, los bellísimos contornos, la delicadeza del colorido, la morbidez y frescura de las carnes, lo seguro del toque, y la gracia con que están agrupadas estas dos figuras son calidades cual mas relevantes de esta preciosa produccion, y por las cuales conjeturan muchos inteligentes que es obra del famoso Corregio. El celage obscuro, y que propiamente figura la noche, da todavia mas realce á la brillantez del colorido de las figuras. Está pintado sobre tabla, y tiene de alto un pié [?], y de ancho diez pulgadas. Esta perfectamente conservado ${ }^{90}$. [Al marge esquerre i signat A. de Cabanyes: «Annibal Carraccio. Nacio en Bolonia en i 560 y murió en Roma en I609. Escuela ecléctica boloñesa. A. De C.».]

$\mathrm{N}^{\mathrm{o}}$ 73. Retrato antiguo. De autor desconocido. Escuela Sevillana. Atendido lo muy obscurecido que se hallan los ropajes y peinado de esta figura, lo gritado de todo el cuadro, y lo mucho que se conoce ha debido sufrir, es algo difícil de poder determinar, ni aun conjeturar el personaje que representa, y á cual época pertenezca, ni casi a cual sexo. Sin embargo los bucles castaños de que está cubierta su cabeza y que le caen en melenas hasta los hombros, parecen indicar un momento en lo mas florido de la edad, y la noble seriedad de su bello rostro, una persona de distinción; siendo casi una prueba también de esto, el que una mano maestra se ocupara en retratarla. $\mathrm{Y}$ en efecto, la singular expresión que reina en todo este semblante ha hecho guzgar a algunos que era obra del gran Murillo; al paso que otros fundados en la frescura y belleza del colorido lo clasifican entre lo mas granado en su clase, Escuela flamenca. Aquí se ha puesto casi involuntariamente de la Escuela Sevillana. Tiene de alto un pié con 8 pulgadas y media, y de ancho un pié con 4 media pulgadas ${ }^{91}$.

$\mathrm{N}^{\circ}$ 74. Jesus coronado de espinas. De Antonio Van Dyck [ratllat en llapis i escrit «Miguel»]. Escuela Fla- 
menca. El cuadrito de este numero es propiamente una miniatura, siendo admirable que lo concluido de la obra, no le dé, cual suele amenudo, ninguna dureza, ni le quite aquel vago del ambiente, que es una de las calidades peculiares á las excelentes producciones de esta clase entre los flamencos; y sobre todo con respecto al insignisimo maestro de quien se supone ser la presente pintura. Fuera por demás detallar aquí las otras muchas prendas de esta bellísima composición, superior sin duda á todo encomio, y sobre la cual reposa siempre tan gratamente la vista. No podemos menos de señalar la idea rara de haber cubierto la facha de uno de los sayones con la propia mano. Esta pintado sobre cobre, y tiene de alto diez pulgadas, y de ancho 7 pulgadas con 8 lineas ${ }^{92}$.

$N^{o} 75$. Dos Santos capuchinos sobre unes nubes [figura I6]. De Bayeu. Aragonés. Lo que particularmente distingue esta bellíssima composición del famoso pintor aragonés es el tono caliente que domina en toda ella, y que presenta de un modo misterioso el ambiente de una región superior a la terrena. Al parecer, es el asunto una visión ó rapto místico, como lo indica la gloria en que se coloca y la Faz majestuosa del eterno que se percibe en la parte superior. El santo que tiene en sus brazos al niño Jesús figura San Félix Capuchino. Es imposible describir el encanto con que parece está pintado este cuadro tan excesivo, y tanta expressión hay en las figuras que ha motivado a que algunos muy inteligentes censores, negasen tanta habilidad á Bayeu, y lo sospecharan obra de pincel todavía mas afamado. Parece que está pintada sobre lienzo, aunque muy pegado a una tabla. Tiene de alto un pié con 5 pulgadas y [...] y de ancho I pié con $6[\ldots]^{93}$.

$\mathrm{N}^{\circ} 76$. San Juan predicando. De autor desconocido.Y en aquellos días vino Juan el Bautista predicando en el desierto de la Judea. Y diciendo: Haced penitencia, porque se ha acercado al reino de los cielos. Pues este es de quien habló el Profeta Isaias diciendo: Voz del que clama en el desierto. Aparejad el camino del Señor: Haced derechas sus verdas. Y el mismo Juan tenia un vestido de pelos de camello, y su ceñidor de cuero alrededor de sus lomos; y su comida eran langostas y miel silvestre. Entonces salía a él Jerusalén, y toda la Judea, y toda la tierra de la comarca del Jordan. Y eran bautizados por él en el Jordan confesando sus pecados. Mas viendo que muchos de los Phariseos, y de los sadduceos venían á su Bautismo, les dijo: Raza de vivoras; quien os á enseñado a huir de la ira venidera? Haced pues fruto digno de penitencia. Y no querrais decir dentro de vosotros; a Abraham tenemos por padre. Porque os digo, que poderoso es Dios para levantar hijos á Abraham de estas piedras. Porque ya esta puesta la segur á la raíz de los arboles. Pues todo árbol que no hace buen fruto cortado será, y echado en el fuego. Yo en verdad os bautizo en agua para penitencia: mas el que he de venir en pos de mi, mas fuerte es que yo, cuyo calzado no soy digno de llevar. El os bautizará en Espíritu Santo, y en fuego. Su bieldo en su mano está y limpiaba bien su era, y recogerá su trigo en el granero; mas quemará las pajas en fuego, que no se podrá apagar jamás. Evangelio de San Matheo. Cap. III. Parece que el autor de esta pintura

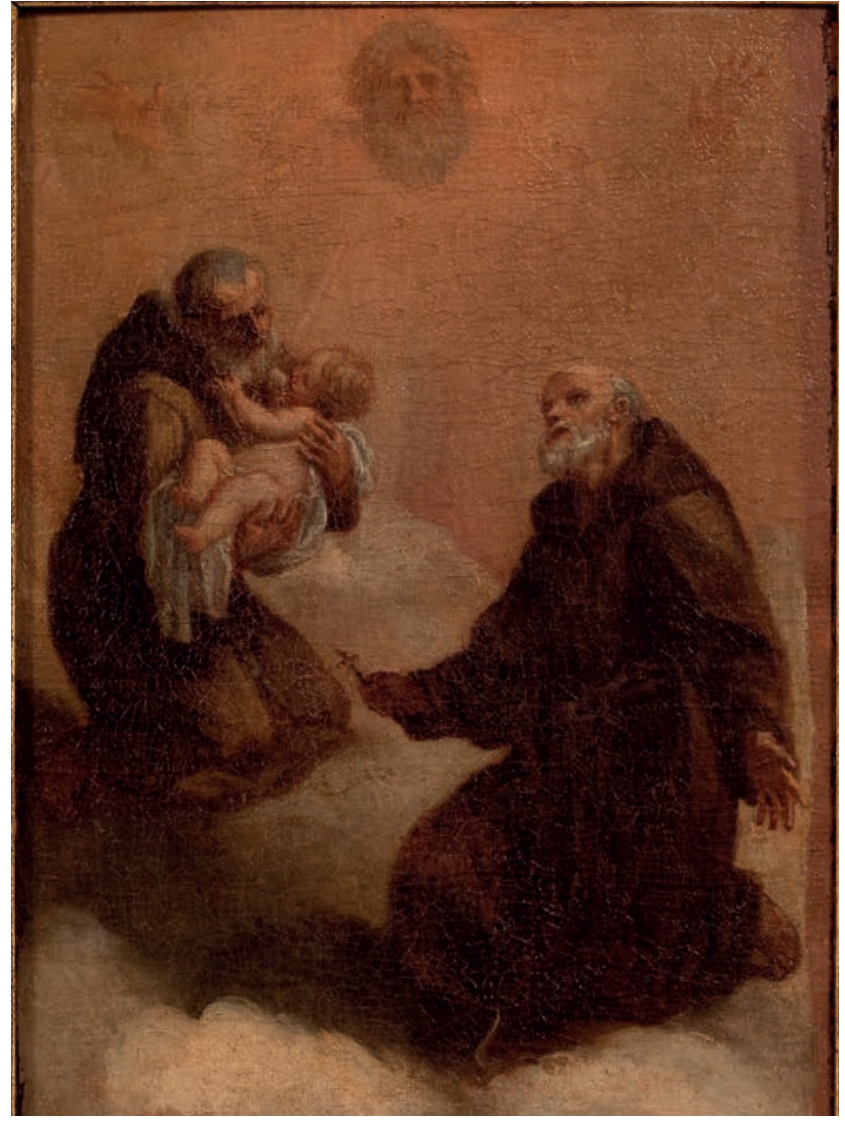

Figura 16.

Francisco BAYEU (?), Dos sants captxins, Masia d'en Cabanyes. Fotografia: Masia d'en Cabanyes. Arxiu fotogràfic del Centre d'Interpretació del Romanticisme Manuel de Cabanyes. Autors: Diego Calderon i Carles Andreu.

tenia bien presente el pasage que acabamos de citar del Evangelio cuando concibió su obra y lo contó con tanta precisión y arte. Aunque haya en la escena una porción de figuras, la del personaje principal se desprende de las demás, y deja percibir todas las señales de la austeridad en que vivía. Tambien se conoce en la erguida figura de la izquierda al presumido Phariseo; y tal vez la del impio sadduceo en el que les está hablando. Las demás, agrupadas con el arte mas bello, parecen ser el pueblo fiel de Jerusalen que viene á escuchar la voz del Precursor. Tiene de alto un pié con 2 pulgadas, y de ancho un pié con 7 pulgadas $^{94}$. [Amb llapis, al final del text, hi diu «Cambiado».]

$N^{\circ}$ 77. El niño Moisés salvado. Del mismo autor que el precedente. «Los hijos de Israel (estando en Egipto) crecieron y se multiplicaron como la yerba [...] y levantose entre tanto un nuevo Rey sobre Egipto, y dijo: Ved ahí el pueblo de los hijos de Israel que es mas fuerte que nosotros; venid y oprimamosle, no sea que se una á nuestros enemigos. Y aborrecían los egipcios a los hijos de Israel, y los afligían con toda suerte de servidumbre, [...] y Pharaon su rey mandó que: Todo varon que naciese lo echasen en el rio [...] y una mujer de Levi parió un hijo: y viéndole que era hermoso, le tuvo escondido tres meses; pero no pudiendo ocultarle ya tomo una cestilla de juncos, y la calafateó con betún y pez, y puso dentro 
al niño, y lo abandonó en un carrizal de la orilla del rio. Parandose a lo lejos una hermana suya, y observando el paradero del caso. Y he aquí que descendia la hija del Pharaon para lavarse en el rio, y sus doncellas andaban por la margen del rio. La cual luego que vió la cestilla en un carrizal, envió una de sus criadas, y habiéndola trahido, abriéndola y viendo en ella un niño, que lloraba, compadecida de él, dijo: De los niños de los Hebreos es este. A la que la hermana del niño dijo: ¿Quieres que vaya a llamarte una mujer hebrea, que pueda criar al niño? Respondió: anda. Fué la doncella y llamó a su madre. A quien hablo la hija de Pharaon diciendo: Toma ese niño y criamelo: ya te daré su salario. Tomó la mujer al niño y criolo; y después que era ya crecido lo entregó a la hija de Pharaon. Al cual ella adoptó en lugar de hijo, y llamó su nombre Moisés, diciendo: Porque del agua lo saqué».Exodo. Cap. I y II. En esta composicion no siguió su autor, que ciertamente es el mismo del numero anterior, tan exactamente el texto como en aquella; pues, imitando lo que hizo Poussin en asunto igual, en vez de la criada que según dice la Escritura mandó la Princesa en busca de la cestilla, vemos á un hombre, y es fuerza confesar que tanto este, como el niño no es lo mas bonito del cuadro. La hija de Pharaon y sus doncellas están bien agrupadas. Es del mismo tamaño que el preceden$\mathrm{te}^{95}$. [Amb llapis, al final del text, hi diu «Cambiado».]

$\mathrm{N}^{\circ}$ 78. Visitacion de Nuestra Señora á Sta. Isabel. De autor desconocido. Aunque las figuritas que representan en el presente cuadro la visita que la Virgen Santisima hizo á su Prima están bastante bien dibujadas y tocadas, siendo copiadas de un cuadro de Mignard, el principal merito de el consiste en la parte de paisaje, que se conoce ejecutado por una imaginación rica, y por una mano hábil en esta clase, pues que el cuadro citado de Maignard no tiene Paisage. Lastima que está muy deteriorado, y que haya sido estropeado por quien seguramente queria limpiarlo. $\mathrm{Su}$ actual posesor lo ha mandado forrar. Tiene de alto un pié con Io pulgadas, y de ancho dos piés con 8 pulgadas. [Amb llapis, al final del text, hi diu «Cambiado».]

$\mathrm{N}^{\circ}$ 79. Presentacion del Hijo de Dios al Templo. Del mismo autor que el anterior. Seguramente que para satisfacer su gusto favorito el autor de esta pintura (el mismo que el de la precedente) ocupa casi todo su lienzo con la representación de un pais, pues solo á la derecha y en primer plano se ve una colunata que parece indicar el atrio del Templo debajo del cual se encenta? $\mathrm{El}$ augusto Misterio. No sabemos si las figuras son copiadas como las del anterior número, lo que no fuera de admirar, pues repetimos, que se conoce que el autor era hábil en paisaje, y muy amenudo los duchos en esta clase no lo son en la figura. El árbol de la derecha es tocado con mucho arte. Tiene las mismas dimensiones que el precedente numero. [Amb llapis, al final del text, hi diu «Cambiado».]

$\mathrm{N}^{\circ}$ 80. San Juan adorando al niño Jesus. Del mismo autor que los dos precedentes. Damos este titulo al presente cuadro, pues que solo es fácil reconocer en él al niño Bautista arrodillado, y admirando á otro niño que esta tendido y rodeada su cabeza de una aureola. Una mujer que lleva una corona real á la cabeza, también arrodillada entre los dos, levanta con su mano izquierda un velo que cubria al Celeste Niño, al paso que ciñendo con su brazo derecho las espaldas del joven Bautista, parece que se lo presenta. Pero si a pesar del distintivo regio que adorna á dicha mujer, se ha de suponer que sea la Madre del Salvador, no es tan fácil adivinar quien puede ser el hombre que mas a la izquierda del cuadro y también en primer plano, pasa un arroyo, encima una cabalgadura. Nada en el indica ser el esposo de Maria. Por lo demas, este cuadro que es del mismo autor que los dos precedentes, es el mas bello de todos. Las figuritas son muy bien pintadas (no sabemos si copiadas) y la parte del paisaje es hermoso; sobretodo el árbol debajo del cual pasa la tierna ecena. El agua del arroyo tiene también mucha transparencia, y los peñascos que baña son tocados con maestria. Es del mismo tamaño que los dos precedentes. [Amb llapis, al final del text, hi diu «Cambiado».]

№ 8I. Cuerpo de Guardia, ó Soldados jugando á naipes. De autor desconocido, y de Escuela Flamenca. Debajo de un entoldado, frente de un edificio, y sentados alrededor de un tambor de guerra, se ven dos militares, cuyo trage parece ser del siglo i6, que estan jugando á naipes. Entre las dos figuras un tercero que parece espectador, y mas al fondo un anciano que conduce á una mujer joven. A la derecha y en segundo plano, se ve á otra mujer sentada con una criatura en su regazo; y a la izquierda casi detrás de uno de los jugadores otro militar embozado y con pluma al sombrero; mientras en plano mas lejano se vé á otro a caballo. Una bandera medio desplegada, y apoyada encima de un tonel, un cofre de viage, un caldero, y unos petos y corazas ocupan todo el primer termino á mano izquierda. El total de esta composición es bello, sobre todo la figura principal que está muy bien puesta. Los accesorios están tocados con mucha maestria y el colorido es rico y armonioso. Está pintado sobre una plancha de hierro, y parece que los colores estan preparados con barniz. Es de forma elíptica, y tiene de alto muy de ro pulgadas, y de ancho un pié con 4 pulgadas y 7 lineas.

$\mathrm{N}^{\circ}$ 82. Pais. Solar antiguo de Cabanyes. De Dn Joaquin de Cabanyes. Si bien esta composición es grata a la vista a pesar de su extremada sencillez, sobretodo por lo acordante de su colorido, su mayor merito, a lo menos para su actual posesor, es el representar la casa solar de sus mayores y en donde nació su abuelo paterno. Situada entre unos bosques en el termino de Argentona á dos leguas de Mataró, este grandioso y solido edificio es un testimonio de la antigüedad y lustre de su familia, y el Escudo de las Armas de su casa soportado por las águilas Imperiales que se ve entre los dos balcones, el busto del Emperador Carlos V que se halla encima del balcón principal, como recuerdo de haber alojado allí aquel soberano; el terreno que hay á cada uno de los cuatro ángulos del edificio, y las almenas que adornan el muro del baluarte todo indica a la evidencia la nobleza y distinción que de siglos gozaba la familia de Cabanyes. Está pintada sobre hoja de lata. Tiene de alto 7 pulgadas con $9[\ldots]$ y de ancho I I pulgadas ${ }^{96}$. 


\section{Apèndix documental 2}

Apéndice. Habiendo, después de la formación de ese Catálogo, cambiado muchísimos cuadros de los que indico, y adquirido otros, pongo la presente nota. Hasta que pueda reformarlo y corregirlo. Los números señalados con X están en Barcelona.

[Text mecanoscrit per Joan Rius el I957 a partir d'un manuscrit a hores d'ara perdut de Josep Anton de Cabanyes intitulat Apéndice, on fa relació d'un inventari que amplia el Catálogo. Biblioteca Víctor Balaguer, Fons Rius, Cat (G).

Nota: només hi transcrivim aquelles obres que, en la descripció, difereixen de les entrades del Catálogo. La X els emplaça a Barcelona.]

Ir. Mujer tocando la guitarra y otros músicos. I 8.2 I [ample] $=30.7 \mathrm{I}$ [alt] $\mathrm{X}^{97}$

I 2. Anacoreta JOANNES. $9,8=7,4 \mathrm{X}^{98}$

I3. La Virgen desconsolada. 2,8 $=3,7 \mathrm{X}^{99}$

I6. Retrato de Golilla. I,5 1/2 = I'9 $X^{100}$

17. David con el arpa $6, \mathrm{IOL}=\mathrm{I} \mathrm{X}^{101}$

32. Porta cruz sobre tabla antigua $6, \mathrm{IL}=8.9 \mathrm{~L} \mathrm{X} \mathrm{X}^{102}$

36. Porta Cruz y sayón de Flauger $8,6=10,4 L^{103}$

37. Sacra Familia buena 2.I.7 $=3.6 .8 \mathrm{X}^{104}$

38. Enarbolamiento de la Cruz I $4.2 \mathrm{~L}=19 \mathrm{X}^{105}$

4I. Ángel o genio 2I,3 I $=25,8 X^{106}$

43. Retrato antiguo de muger $\mathrm{IO}=\mathrm{I} 3^{107}$
44. Una mano escribiendo $20.9=16.5 \mathrm{~L} \mathrm{X}^{108}$

45. Unos Libros $20,4 \mathrm{~L}=\mathrm{I}_{4} \mathrm{X}^{109}$

66. Sacra Familia de S. Vernet $5,3=3,6^{110}$

76. De Joaquín. Vista de Segovia I $4=\mathrm{I}_{2} \mathrm{X}^{11}$

78. Labrador y Labradora conduciendo ganado 9,6 $=\mathrm{I} 3$ $\mathrm{X}^{112}$

79. Cuerpo de Guardia. Ovalado $1,4,7=10$ pulg ${ }^{113}$

80. De Joaquín. Solar antiguo de Cabanyes I I $=7,9^{114}$

8. Testa de Ribalta I I $=$ Is $\mathrm{X}^{115}$

82. Bañistas de Viladomat I $5,9=9,9 X^{116}$

83. Salomé recibiendo del verdugo la cabeza del Bautista $2, \mathrm{II}=2,2^{1 / 2} \mathrm{X}^{117}$

84. Testa de muger flamenca $\mathrm{I}, 5^{1 / 2}=\mathrm{I}, 9 \mathrm{X}$

85. San Gerónimo escribiendo $2=2,6 \mathrm{X}^{118}$

86. Alegoría de la poesía. $\mathrm{H} . \quad \mathrm{I} 6.8=19,7 \mathrm{X}$

87. Testa de viejo I $5^{1 / 2}=19,3 \mathrm{X}$

88. San Francisco de Asís 2,3 = 2,10 1/2 $\mathrm{X}^{119}$

90. Pescador de Ferrán 2,2 = I, $7 \frac{1 / 2}{X}$

91. Copia del Mago de Rembrandt is $1 / 2=20$ y 4 (lin. que se puede cortar) ${ }^{120}$

92. Interior de la iglesa del Corpus Christi $0=\mathrm{I}_{3} \mathrm{X}^{121}$

93. País de Luna de Joaquín sobre hojalata 10,4 $\times 7,7 \mathrm{X}^{122}$ 94. Marinita de Joaquín $\mathrm{IO}, 2=7 \mathrm{X}$

95. Boceto del Puerto de Barcelona de Joaq. $9=4 \mathrm{X}$

96. Santa Cecília y un coro de ángeles I 2,8 = I7 X

97. Santa Rosa de Lima 3,5 $=4,51 / 2 \mathrm{X}^{123}$

98. Busto de papel sobre cobre $7=9,5 \mathrm{X}$ 
1. Aquest article ha rebut el suport dels recursos del projecte d'investigació Arte, oficio y mercado: La condición del artista en Cataluña y Baleares durante los siglos XV al XVIII (Ministerio de Economía y Competitividad, HAR2015-66465C2-1-P).

2. Manuel SAurí i José Matas (1849), Manual histórico-topográfico estadístico y administrativo o sea Guia general de Barcelona [...], Barcelona, Imp. de Manuel Saurí, p. 177-179.

3. Un estat de la qüestió en forma de síntesi compilatòria es pot trobar al capítol «El col-leccionisme eclesiàstic decimonònic $\mathrm{a} \mathrm{Ca}$ talunya», a: Gabriel Alcalde i Francesc Miralpeix (2014), Passió col-leccionista: El museu-biblioteca de Mossèn Pere Valls $i$ Vila (18481925), Perpinyà, Presses Universitaires de Perpignan, p. 13-26.

4. Vicente Maestre (2007), «Las primeras exposiciones retrospectivas, coleccionismo y museos: Temas para un capítulo de la historia del arte en la Barcelona de la Restauración», editat per Bonaventura Bassegoda, Col-leccionistes, col-leccions i museus: Episodis de la historia del patrimoni artístic de Catalunya, Barcelona et al., Universitat de Barcelona et al., p. 59-119. Per tenir una panoràmica general del fenomen, és indispensable consultar Francesc FonTbona (1987), «El col-leccionisme català del Romanticisme al Realisme», Serra d'Or, 335 (setembre), p. 60-61 [652-653]. Del mateix autor, vegeu (2001) «Associacionisme, mecenatge i colleccionisme d'art entre els burgesos catalans del segle XIX», Revista de Catalunya, 160 (març), p. 5977.

5. Per la conformació dels aspectes tocants a la personalitat de Josep Anton de Cabanyes, ens han estat útils els treballs de Joan [RIUs I VILA] (1973-1974), «Els Cabanyes es perden en la llunyania dels temps», Diari de Vilanova: Miscel-lania Vilanovina, 6 d'octubre de 1973, p. $15 ; 20$ d'octubre de 1973 («Els Cabanyes es perden en la llunyania dels temps. 2on»); p. 19, 11 de novembre de 1973 («L'edat d'or dels Cabanyes vilanovins. ler Llorens de Cabanyes i Fuster»); p. 17, 8 de desembre de 1973 («L'executòria de noblesa dels Cabanyes acompanyada del daltabaíx de Nápols»); p. 13, 26 de gener de 1974 («Anys de prova (1808-1814): Llorens de Cabanyes bon timoner»); p. 15, 23 de març de 1974 ( «La Masía d'En Cabanyes en el seu punt àlgid: Espiritualment parlant-Malaltia i mort del poeta»); p. 7, 27 d'abril de
1974 («De quina manera la Masía d'en Cabanyes resta convertida en monument sepulcral»); p. 19, 18 de maig de 1974 («Llorenç de Cabanyes i d'Olzinelles conserva i augmenta el prestigi de la masia»); p. 15, 25 de maig de 1974 («"La cansó d'en Francesch de Vílanova de Cabelles" (Tradició) per Llorens de Cabanyes»); p. 15, 4 d'agost de 1979 («La Masia d'En Cabanyes: El seu passat, el seu present i el seu futur incert»); Joan RiUS I VILA (1956), «El noble señor D. José Antonio de Cabanyes y Ballester», Boletín de la Biblioteca-Museo Balaguer, 5a època, tom. Iv, p. 3-22; ÍDEM (1982), Del Maresme al Penedès i al Garraf a través dels Cabanyes vilanovins: Més de mil anys d'història $i$ de llegenda, Vilanova i la Geltrú, Centre d'Estudis de la Biblioteca-Museu Balaguer; ÍDEM (1986), La vida i l'obra de Manuel de Cabanyes a través de la seva biografia, Vilanova i la Geltrú, Centre d'Estudis de la Biblioteca Víctor Balaguer; Josep Antoni de CABANYES I BALlester (1970), Notas y observaciones hechas en mi viaje y permanència en Mallorca, introducció, notes i comentaris de Joan Rius i Vila, Barcelona, Pòrtic; Oriol PI de Cabanyes (2000), «Avantpassats a Holanda", El sol de Vilanova $i$ el Garraf misteriós, Vilanova i la Geltrú, El Cep i la Nansa; Francesc Xavier Puig Rovira (2003), «Cabanyes Ballester, Josep Antoni», Diccionari biográfic de Vilanova i la Geltrú, Vilanova i la Geltrú, Ajuntament de Vilanova; Oriol PI de Cabanyes (2010), «Cabanyes Ballester, José-Antonio de», Diccionario biográfico espanyol, Madrid, Real Academia de la Historia, 10. La citació correspon a unes notes transcrites per Oriol Pi de Cabanyes de la documentació original de Josep Anton de Cabanyes, parcialment publicades per Rius i Vila.

6. Un cas similar, i també gairebé únic per la meticulositat de les seves catalogacions i dels coneixements que atresorava, és el del canonge Pablo Recio. Vegeu Bonaventura BASSEgODA (2005-2006), «La colección pictórica del canónigo don Pablo Recio y Tello (Yunquera de Henares 1765 - Madrid 1815)», Locus Amoenus, 8, p. 233-264.

7. Conservat a la Masia d'en Cabanyes de Vilanova i la Geltrú. La Masia d'en Cabanyes és propietat de l'Ajuntament de Vilanova i la Geltrú i la gestiona el Consell Comarcal del Garraf. S'hi pot visitar el Centre d'Interpretació del Romanticisme Manuel de Cabanyes. El catàleg va tenir una primera transcripció per part de Blanca Giribet, documentalista, a partir dels ajuts que va concedir la Diputació de Barcelona l'any 2014.

8. Volem expressar el nostre agraïment a Oriol Pi de Cabanyes i a les enriquidores informacions que ens ha facilitat del seu avantpassat. Aquest agraïment ens cal fer-lo extensiu, i de manera molt especial, a Mila Arcarons, de la Masia d'en Cabanyes, que ha vetllat perquè tinguéssim a mà tots els materials necessaris per poder realitzar aquest estudi. Igualment, agraïm la collaboració d'Albert Alentorn, Bonaventura Bassegoda, Mireia Rosich, Xavier Solà, Francesc X. Puig Rovira, Estellla Adell, Alba Tomàs, Blanca Giribert, Montserrat Comas (Biblioteca Víctor Balaguer) i Rafel Mestres (Arxiu Comarcal del Garraf).

9. La citació correspon a unes notes transcrites per Oriol Pi de Cabanyes de la documentació original de Josep Antoni de Cabanyes, parcialment publicades per Rius i Vila, amb petites variants sintàctiques. Cfr. Josep Antoni de Cabanyes I Ballester, Notas y observaciones hechas..., op. cit., p. 61.

10. Josep Antoni de Cabanyes I Ballester, Notas y observaciones hechas..., op. cit., p. 62.

11. Ibídem, p. 61.

12. Ídem.

13. Notes manuscrites per Oriol Pi de Cabanyes a partir de la documentació original. També transcrites a Josep Antoni de Cabanyes I Ballester, Notas y observaciones hechas..., op. cit., p. 61-62.

14. Ibídem, p. 66.

15. Extret de les notes del poema Adiós, amigo Eudaldo, parcialment publicades per Joan Rius i Vila a les notes crítiques del manuscrit de Mallorca. Cfr. Josep Antoni de CABANYES I BALlester, Notas y observaciones hechas..., op. cit., p. 131. La transcripció completa d'aquests apunts versificats ens ha estat facilitada per Oriol Pi de Cabanyes.

16. Notes transcrites per Oriol Pi de Cabanyes d'un llarg poema manuscrit de Josep Anton.

17. La llista de llibres de Josep Antoni de Cabanyes és molt llarga. A banda dels que ingressaren a la Masia d'en Cabanyes, segons un inventari de 1978 intitulat Listado de libros de la casa Cabanyes que han pasado a la familia Miret-Cabanyes, correspondientes a la biblioteca de José Antonio de Cabanyes, hi ha la donació recent de 102 llibres 
en 141 volums més de la Sra. Rosó Miret de Cabanyes com a hereva de la família Miret de Cabanyes. Joan Rius, l'estudiós dels Cabanyes, assegurà que la pràctica totalitat de la biblioteca dels Cabanyes l'aplegà Josep Anton (Joan Rius, «El noble señor D. José Antonio de Cabanyes...», op. cit., p. 18-19).

18. Es feu una edició d'aquest tractat l'any 1757 a Amsterdam, a la casa Westein.

19. Un inventari redactat a la fi del segle xix, de la documentació aplegada per Oriol Pi de Cabanyes, detalla l'existència dels catàlegs següents: Explication des ouvrages de peinture et de sculpture de l'Ecole moderne de France: exposés le 24 avril 1818 dans le musée royal du Luxembourg destiné aux artistes vivants, París, Didot, 1820; Notice des tableaux du musée de Lyon, de François Artoud (1822); Il regal Museo borbónico descritto dal Cav. Giovanbatista Finati (1819); Notice des dessins, peintures, émaux et terres cuites, exposés an Musée royal dans la galerie d'Apollon, París, 1818; Notice des tableaux exposés dans la Galerie du Musée Royal, París (1816, 1819, 1823); Exposition de la societé Royale de Bruxelles (1824); Tentoonstelleing, te Amsterdam, van den Jare (1818), i Notice des tableaux de la Galerie Royale a la Haye (1817).

20. Adrien i Thomas Hope, banquers i comerciants, foren uns dels personatges més rics d'Holanda, directors de la Companyia de les Índies Orientals i fundadors de la companyia Hope \& Co, amb sucursals a les principals ciutats del nord d'Europa. Vegeu Marten G. Buist (1974), At spes non fracta: Hope E Co. 1770-1815. Merchant Bankers and Diplomats at Work, La Haia, Martinus Nijhoff.

21. Nota manuscrita al peu del quadre número 7 de la sèrie. Catálogo y descripción de algunos cuadros que posee Don José Antonio de Cabanyes, c. 1850. Els quadres en qüestió conformen la Història de Josep, cinc dels quals es troben actualment a la Fundació Julio Muñoz Ramonet, de l'Ajuntament de Barcelona. Vegeu Francesc Miralpeix (2014), Antoni Viladomat i Manalt (1678-1755): Vida i obra, Girona, Museu d'Art de Girona, Generalitat de Catalunya, p. 302-304.

22. Josep Antoni de Cabanyes I Ballester, Notas y observaciones hechas..., op. cit., p. 129 i 130.

23. L'atribució d'aquestes pintures a Pau Rigalt, com explica Francesc
Quílez, prové de referències genèriques de la bibliografia, com ara del diccionari d'Elias de Molins, de Casellas o de J. F. Ràfols. L'atribució es deu, sobretot, a criteris estilístics de matriu neoclàssica i al fet que Rigalt, en aquells anys, era el pintor decorativista de referència de les elits burgeses barcelonines. S'esmenta com a argument, també, que Rigalt residí a Vilanova durant la Guerra del Francès, però la decoració de la casa és anterior. Això no obstant, al manuscrit de Josep Anton de Cabanyes (Biblioteca Víctor Balaguer, signatura CAB Not (G)) titulat Notícias cronológicas, geneológicas, biográficas e històrica-económicas de la Casa de Cabanyes en Villanueva y la Geltrú (c. 1822-1849), foli 19, només hi apareix el nom del pintor Tomàs Solanes, que s'havia format a Madrid, a l'ombra de Maella i Mengs, i que estava vinculat a l'Escola de Dibuix de Barcelona. Sobre Pau Rigalt, vegeu Francesc Quílez (1999), «Pau Rigalt i el fenomen de la pintura decorativa a la Catalunya de la primera meitat del s. xix: El conjunt del Cercle Artístic de Sant Lluc i altres aportacions al catàleg del pintor», Butlletí de la Reial Acadèmia Catalana de Belles Arts de Sant Jordi, 13 , p. 127-172.

24. Oriol Pi de Cabanyes (2014), «La petita història de tres peces», Art. Cultura. Economia $i$ societat a la Masia d'en Cabanyes: Visites temàtiques al «Centre d'interpretació del Romanticisme Manuel de Cabanyes", Vilanova i la Geltrú, Consell Comarcal del Garraf, p. 24-29. No deixa de ser curiós que, tot i la importància de la Masia, tant des del punt de vista arquitectònic com des de l'estimació que hi sentia Josep Anton, no figuri en cap anotació dels seus manuscrits més enllà d'algun apunt a l'adquisició dels terrenys.

25. Josep Antoni de Cabanyes BALLester, Notas y observaciones bechas en mi viaje y permanència en Mallorca..., op. cit., p. 100. Es pot llegir una extensa biografia del personatge i de la seva coneguda afició a Marià CARbonell (2013), El Cardenal Despuig: Col-leccionisme, Grand Tour i cultura Il-lustrada, Mallorca, Consell de Mallorca.

26. MdC [Masia d'en Cabanyes], Fons documental, Josep Anton de Cabanyes, Catálogo y descripción de algunos cuadros que posee Dn. José Antonio de Cabanyes: «Advertencia».

27. Imprès a l'Imprimerie Wersembruch, de Brussel-les, l'any 1808.
28. Sobre el tractat, ens ha estat especialment útil l'estudi d'Eveline KoolhaAs-Grosfeld (1987), «François Xavier de Burtin (17431818): Promoteur de la peinture hollandaise en France», Septentrion: Révue de Culture Néerlandaise, 3, p. 29-39. Sobre el personatge, vegeu François de Catallay (2006), «La vie rocambolesque et le cabinet d'étude de François-Xavier Burtin (1743-1818) », La Vie des Musées, 20 , p. $87-93$.

29. François Xavier DE BurTin, Traité historique et pratique des connaissances..., op. cit., 2, p. 73.

30. Ibídem, p. 112-114.

31. Vegeu els estudis de Manuel Ruiz ORTega (1999), La escuela gratuita de diseño de Barcelona. 1775-1808, Barcelona, Biblioteca de Catalunya; Francesc Quílez (2002), «Tendències acadèmiques en l'art català de finals del segle XviıI i principis del segle XIX», Llotja. Escuela Gratuita de Diseño. Escola d'Art, 1775-2000, Barcelona, Generalitat de Catalunya, p. 22-33.

32. Catálogo y Descripción de algunos cuadros..., op. cit., cat. 57.

33. Ídem. El quadre en qüestió, titulat Adonis treu una estella del taló de Venus, figura al catàleg en línia de la RACBASJ. És atribuït a Marco Antonio Franceschini $i$ es troba en dipòsit de la Reial Acadèmia Catalana de Belles Arts de Sant Jordi al MNAC, on té el número d'inventari MNAC 5689 (<https://www.racba.org/ mostrarobra2.php?id=23054; consulta: 9 març 2017>). Francesc Fontbona i Victòria Durá (1999), Catàleg del Musen de la Reial Acadèmia Catalana de Belles Arts de Sant Jordi (I-Pintura), Barcelona, Reial Acadèmia Catalana de Belles Arts de Sant Jordi, Barcelona, p. 28, amb atribució antiga a Albani.

34. Catálogo y Descripción de algunos cuadros..., op. cit., cat. 1.

35. Obras de D. Antonio Rafael Mengs, primer pintor de cámara del rey, publicadas por don Joseph Nicolas de Azara, Madrid, Imprenta Real..., 1797.

36. Juan Agustín CeÁn BermúdeZ (1800), Diccionario de los más ilustres profesores de las Bellas Artes en España, Madrid, Imp. Viuda Ibarra, 5 vols. Hi havia també Le Cicerone de Versailles, ou l'indicateur des objets curieux de cette ville, Versalles, I. Jacob, 1815; o l'enciclopèdia en 16 volums Museo Universal de Pintura y de Escultura y Galería 
Europea de las Artes y de la Historia, Barcelona, Imprenta de Joaquin Verdaguer, 1840.

37. Bonaventura Bassegoda (ed.) (2007), Col-leccionistes, col-leccions i museus: Episodis de la història del patrimoni artístic de Catalunya, Barcelona et al., Universitat de Barcelona et al., p. 9-11.

38. Biblioteca Víctor Balaguer, signatura CAB Not (G): Josep Anton de Cabanyes, Notícias cronológicas, geneológicas, biográficas e historicaeconómicas de la Casa de Cabanyes en Villanueva y la Geltrú (c. 18221849), foli 55. Còpia mecanografiada del manuscrit inèdit realitzada per Rius i Vila. Agraeixo a Montserrat Comas les facilitats per poder consultar el mecanoscrit.

39. Notícias cronológicas, geneológicas, biográficas..., op. cit., pàssim. Segons el manuscrit, el 27 de setembre era a Amsterdam, acollit a la casa de la Sra. Berkembosch; el 1820 passà a Anglaterra i, d'allí, aquell mateix any, travessà França, anà cap a Suïssa i recorregué Itàlia de cap a cap, fins a Nàpols, gairebé com si es tractés del trajecte tradicional que solien fer els viatgers del Grand Tour. El 1822, tornà a Holanda via Estrasburg i d'allí a Brussel-les, el 1823, on s'hi estigué fins al 1824. Aquell any tornà, com ja s'ha dit més amunt, per fer-se càrrec dels negocis familiars que, des de la mort del seu pare, el 1814, regentava la seva mare Catalina $\mathrm{Ba}$ llester de Carro, casada en segones núpcies amb Llorenç Cabanyes i Fuster.

40. Cecili Padró Lluçà (1960), «El Barón de Taylor en Barcelona», Divulgación Histórica, Barcelona, XI, p. 219. Per les enormes possibilitats que presentava el mercat barceloní, vegeu F. Alcolea (2013), Hacia unas aportaciones sobre el mercado del arte en Barcelona en la primera mitad del siglo XIX, autoedició digital: <https://www. academia.edu/5179511/Hacia unas_aportaciones_sobre_el_mercado_del_arte_en_Barcelona_en_la_ primera_mitad_del_siglo_XIX >

41. Carta de Josep Anton al seu germà Joaquim ( 4 de gener de 1844). Cortesia d'Oriol Pi de Cabanyes.

42. Notícias cronológicas, geneológicas, biográficas..., op. cit., foli 65, 14 de desembre de 1844 .

43. Coneixem la referència del testament gràcies a Estel Adell. El document es troba a l'Arxiu Comarcal del Garraf, Fons Cabanyes.
44. ACG, Fons Cabanyes. «Protocolización de inventario, valoración $\mathrm{y}$ adjudicación de las herencias de Lorenzo de Cabanyes y Olzinellas y de Leonor Marqués y Riba, entre sus hijos». Notari de Vilanova i la Geltrú, Alfonso Grande Canosa, 31 de gener de 1895.

45. La descripció parteix de la tasca realitzada per la documentalista Blanca Giribert.

46. L'observació és de Francesc Fontbona.

47. Joan SACs (pseudònim de Feliu Elias) (1918), «El suposat Guido Reni de la colllecció Cabanyes», Vell i Nou, IV (67), 15 de maig, portada i pàgines 196-197. L'autor -Joan Sacs? - descarta que es tracti, amb bon criteri, d'una obra del bolonyès.

48. Joaquim de CAmps i Arboix (1965), Les cases pairals catalanes, fotografies de Francesc Català Roca, Barcelona, Destino. Es pot veure amb més claredat a ACG, Fons fotogràfic Monrós, referència R001-001. Donació al Consell Comarcal del Garraf de Ricard Monrós. Les fotografies són d'Antoni Monrós i Valls. Es tracta d'una mitjacanya amb la representació allegòrica de les Arts, molt deutora de l'estil de Mariano Salvador Maella, ara propietat de Maria Pilar Ochoa, filla de Marta de Cabanyes, casada amb Albert Alentorn, a qui volem agrair l'amabilitat a l'hora de mostrar-nos-el. Joaquim de Cabanyes i Ricart, fill d'Alexandre de Cabanyes, consta que es vengué a Sotheby's una obra propera a la tipologia de peces que podrien haver format part del gust de Josep Anton de Cabanyes. Es tracta de l'Al-legoria de l'aire atribuïda al taller de Jan Brueghel el Jove. Sotheby's. Old MasterE British paintings (2012), catàleg de la subhasta, Londres, 6 de desembre, lot. 113 (reproduit).

49. Relación numerada de cuadros existentes en Masia Cabanyes, con autores y precio aprox. s/ dictamen de Don José Gudiol, Director del Instituto Amatller, en visita efectuada el 6 de Octubre de 1973. Agraeixo a Xavier Solà que me'n facilités una còpia.

50. Arxiu Municipal de Vilanova. Document notarial de l'escriptura de cessió de la Masia d'en Cabanyes a l'Ajuntament de Vilanova i la Geltrú el 14 de maig de 1975: Inventario de los cuadros existentes en la planta noble del edificio "Masia Cabanyes", propuestos para ser cedidas al ayuntamiento de esta
Ciudad por los hermanos Sres. De Cabanyes y Ricart, redactado a la vista de las obras, redactat el 2 de juliol de 1974.

51. Sis quadres de la sèrie «Història de Josep", d'Antoni Viladomat, foren venuts a Flocel Puig Vila (tots menys el número 4 , que passà a Marta de Cabanyes i posteriorment a Pilar Ochoa de Cabanyes). Cinc dels quadres venuts i que havien estat propietat de Carles de Cabanyes (germà d'Alexandre de Cabanyes) passaren a la collecció de Julio Muñoz Ramonet (es tracta dels quadres amb els episodis Josep venut pels seus germans; La túnica de Josep; Josep interpreta els somnis del faraó d'Egipte; Josep, convertit en un personatge destacat, amonesta els seus germans, i Josep es dóna a conèixer i abraça Benjamî). Aquests quadres havien estat al Castell de Berà. L'any 1959, Flocel Puig va vendre la finca a una societat hispanobelga formada per Rene Vandemeuter i Pedro Sureda, i és probable que fos llavors quan entressin al mercat. Del restant, Josep i la dona de Putifar (núm. 3), se'n desconeix la ubicació actual. Cfr. Francesc Miralpeix, Antoni Viladomat..., op. cit. p. 302-304.

52. Actualment, a la col-lecció Pilar Ochoa de Cabanyes.

53. Masia d'en Cabanyes, inventari general, en endavant $\mathrm{MdC} /$ inv. gen. $99.27,5 \times 32,5 \mathrm{~cm}$. Josep Anton consignà un seguit de quadres del seu germà Joaquim de Cabanyes, pintor i militar. Són paisatges tocats per l'esperit romàntic, amb vistes d'Alcalá de Henares, Segòvia i del seu pas per Mallorca (núms. $8,9,10,53,54,55,56$ i 82). Sobre Joaquim de Cabanyes, vegeu M. Utrillo (1933), «El pintor Joaquim de Cabanyes i els seus», Butlletí dels Museus d'Art de Barcelona, 30, p. 341-349.

54. $\mathrm{MdC} /$ inv. gen. $31.19,5 \mathrm{~cm}$ diàmetre. M. UTRILLO, «El pintor Joaquim de Cabanyes...», op. cit., p. 345 .

55. MdC / inv. gen. $19.5 \mathrm{~cm}$, diàmetre $102 \mathrm{~cm}$. La historiadora Estel Adell considera que no és el mateix quadre de l'inventari, perquè les mides no hi coincideixen, però la descripció i la temàtica sembla que sí. La conversió de les polsades a centímetres només varia en 3 centímetres.

56. $\mathrm{MdC} /$ inv. gen. $64.81 \times 70 \mathrm{~cm}$. L'atribució a l'escola d'Antoni Viladomat és errònia. Podria tractar-se d'una còpia tardana d'una obra napolitana del cercle de Ribera. 
57. $\mathrm{MdC} /$ inv. gen. $32.53,5 \times 66,5$ $\mathrm{cm}$. Es tracta d'una obra de bona qualitat. El paisatge amb tonalitats rosades i amb les característiques llums càlides del capvespre no desentonen amb l'atribució proposada al paisatgista Claude Joseph Vernet (1714-1789).

58. MdC / inv. gen. $47.53,5 \times 66,5$ $\mathrm{cm}$. L'atribució a Salomon van Ruysdael (1600/1603-1670) és massa generosa, malgrat que les vistes marines amb vaixells recorden la temàtica de les seves obres. És més convenient suggerir una atribució a un pintor anònim holandès de mitjan segle XVII.

59. Ubicació actual desconeguda. Joan SACS (?), «El suposat Guido Reni...», op. cit. Tot i tractar-se d'una obra de bona qualitat, l'autor-Joan Sacs?- descarta que es tracti, amb bon criteri, d'una obra del bolonyès. Ja no figura a les taxacions de 1973 i 1974.

60. Vertumne i Pomone. L'estil i el tema del quadre han fet pensar que podria tractar-se d'una obra de Nicolas Poussin. És més versemblant, no obstant això, atorgar-li una autoria anònima a l'entorn de l'escola romana de mitjan segle xvir. Es conserven fotografies del fons Monrós de l'Arxiu Comarcal del Garraf, en endavant ACG, on es veu al seu emplaçament original. A l'inventari de 1973, hi apareix marcat amb una $X$, que indica que fou apartat de la cessió. Actualment, forma part de la col-lecció Pilar Ochoa de Cabanyes.

61. $\mathrm{MdC} /$ inv. gen. $113.92 \times 73$ $\mathrm{cm}$. No estem segurs que pugui tractar-se d'aquesta obra, per bé que la descripció li és molt propera. Si és el cas que ho sigui, l'atribució a Zurbarán s'ha de reconsiderar a favor d'una adscripció a l'escola napolitana de principis del segle XviII.

62. Aquesta obra fou recollida per Feliu Elias, que coneixia el manuscrit. Se'n desconeix la ubicació actual. Cfr. Francesc Miralpeix, Antoni Viladomat..., op. cit., p. 492.

63. $\mathrm{MdC} /$ inv. gen. $17.46 \times 34 \mathrm{~cm}$.

64. MdC / inv. gen. $14.46 \times 35,5$ $\mathrm{cm}$. Un figón és una casa on se serveix de menjar i que es considera, normalment, de poca categoria.

65. El catàleg de Josep Anton descriu un seguit d'obres atribuides a Salvatore Rosa que no s'han conservat. Per les descripcions, devien tractar-se de capricci arquitectònics, potser adquirits durant la seva esta- da a Nàpols, que eren molt del gust dels viatgers del Grand Tour.

66. $\mathrm{MdC} /$ inv. gen. $39.26 \times 35,5$ $\mathrm{cm}$. El fet que es tracti d'un oli sobre coure fa pensar en una adscripció estilística flamenca, de la segona meitat del segle XviI.

67. $\mathrm{MdC} /$ inv. gen. $38.29 \times 39 \mathrm{~cm}$. Les formes dolces d'aquest petit quadret, que identifiquem amb el número 38 de l'inventari general de la Masia, degueren suggerir al seu propietari una adscripció murillesca. És probable que es tracti d'una obra de context sevillà o granadí.

68. Tot i que no es conservi, és interessant subratllar el fet que Josep Anton conegués l'obra de Joaquim Juncosa i que s'hi interessés. Les indicacions biogràfiques que dona demostren la seva formació i el coneixement dels autors catalans. Val la pena de fer notar, d'altra banda, l'interès per col-leccionar pintors del barroc català, com el mateix Juncosa, Viladomat o Montanya.

69. $\mathrm{MdC} /$ inv. gen. $10.41 \times 30$ $\mathrm{cm}$. L'atribució a l'escola valenciana - potser a l'entorn d'Orrentesembla enraonada. Darrere hi ha un anagrama dibuixat on s'endevinen les lletres P, E, O, D i R.

70. $\mathrm{MdC} /$ inv. gen. $1.35 \times 48 \mathrm{~cm}$. $S$ 'ha interpretat que podria tractar-se del setge de Viena de 1683 (fitxes de l'inventari de la Masia d'en Cabanyes). També podria referir-se al setge d'Oran de 1732. L'atribució al cercle de Jacques Courtois no és pas desencertada.

71. $\mathrm{MdC} /$ inv. gen. $257.46 \times 58$ $\mathrm{cm}$. L'abundància de figures en aquest Baptisme i els tons naturalistes dels figurants feren que Josep Anton pensés en l'autoria de Jacopo da Ponte. No obstant això, les citacions a figures repoussoir i a estudis acadèmics de nu, com ara l'home que es vesteix d'esquena, disposats sense gaire gràcia i amb desproporcions anatòmiques, aconsellen vincular l'obra al classicisme acadèmic, potser fins i tot d'escola espanyola a l'entorn de Pedro Orrente, segons observació feta per Bonaventura Bassegoda, però en cap cas propera als pintors de Bassano.

72. No tenim cap seguretat que es tracti d'aquest quadre que es pot contemplar en una de les fotografies de la casa de l'ACG, Fons Ricard Monrós, referència R001-002. A l'inventari de 1973, hi apareix un quadre amb el número de catàleg 124 que diu «Escuela napolitana, Niño dormido con ángeles», valorat en 250.000 pessetes. Per la fo- tografia, s'hi endevina una obra de qualitat que copia d'una versió atribuïda a Guido Reni d'una colllecció privada genovesa (Fondazione Zeri, Catalogo Fototeca 116450), de la qual en circularen algunes còpies al mercat antiquari.

73. Pensem que podria tractar-se de l'obra MdC / inv. gen. $93.63 \times$ $52 \mathrm{~cm}$.

74. $\mathrm{MdC} /$ inv. gen. $57.35,5 \times 47,5$ $\mathrm{cm}$. Es tracta de dos capricci arquitectònics (núms. 47 i 48) de molt bona qualitat, per bé que l'atribució a Salvatore Rosa és qüestionable. Recorden, en canvi, la pinzellada més estirada i colorista del napolità Niccolò Codazzi (1642-1693), en l'estil del qual també ens hi fan pensar per la seva fecunda imaginació.

75. $\mathrm{MdC} /$ inv. gen. $60.36 \times 47 \mathrm{~cm}$.

76. Josep Anton va ser un dels col-leccionistes més primerencs de l'obra d'Antoni Viladomat (cfr. núms. 49, 50, 51 i 52). En aquest cas, a més, destaca la qualitat $i$ el nombre d'obres de temàtica de gènere que tingué del pintor barceloní. Les pintures arribaren a les seves mans a través de la branca familiar de la seva mare, Caterina Ballester de Carro. El número 49 l'heretà del seu oncle Juan Bautista Ballester de Carro, que el tenia juntament amb els tres restants que venen a continuació —corregim aquí les apreciacions de Francesc MIRALPEIX, Antoni Viladomat..., op. cit., p. 393-395. A la mort del seu oncle Juan Bautista, Josep Anton en va anar aplegant els tres restants. El número 50 el comprà a la vídua de l'oncle, i el 51, a l'altre germà, José María Ballester de Carro. El darrer, el 51, li cedí la seva tia Maria Antònia Garcesa, de Tarragona. Els Ballester de Carro van emparentar amb els Cabanyes l'any 1786, quan Josep Ballester i Ferret s'esposà amb Rosa Cabanyes i Rovira. La seva filla Caterina es casà amb el vidu Llorenç de Cabanyes i Fuster, l'any 1795. Raymundo Ferrer, a la Barcelona cantiva, diu que Juan Bautista era subtinent el 1821. De José Maria, en sabem que pagà pel projecte d'altar dedicat a sant Isidre, a Vilanova. Vegeu Cèsar MarTinell (1948), «El escultor Luis Bonifás y Massó, 1730-1786: biografía crítica», Anales y Boletín de los Museos de Arte de Barcelona, 6, p. 188.

77. $\mathrm{MdC} /$ inv. gen. $97.27,5 \times 32 \mathrm{~cm}$.

78. $\mathrm{MdC} /$ inv. gen. $96.27,5 \times 32,5$ $\mathrm{cm}$.

79. $\mathrm{MdC} /$ inv. gen. $29.30,5 \times 23,5$ $\mathrm{cm}$. És probable que els arcs de 
ferradura li fessin confondre l'espai de l'església del Corpus Christi de Segòvia amb l'Alhambra. L'interior de l'església del Corpus Christi de Segòvia es va perdre en l'incendi de 1899.

80. MdC / inv. gen. $100.25 \times 18$ $\mathrm{cm}$.

81. MdC / inv. gen. 33. Tal com diem a la nota 33, l'original, comprat el 1806 per la Junta de Comerç per al Museu de l'Escola de Belles Arts de Barcelona, a Llotja, és ara en dipòsit al MNAC (vegeu Francesc Fontbona i Victòria Durá (1999), Catàleg..., op. cit., p. 28).

82. $\mathrm{MdC} /$ inv. gen. $36.90 \times 120$ $\mathrm{cm}$. Aquest grup de pintures de temàtica mitològica (núms. $57,58,59,60$ i 61 ) devien formar un conjunt temàtic dedicat als amors $\mathrm{i}$ a les passions dels déus. És molt probable que es tracti d'una sèrie de quadres d'autors anònims menors d'escola bolonyesa o romana de la primera meitat del segle XvII, que versionaven obres d'Albani, Domenichino, Franceschini, Guercino i altres pintors del classicisme bolonyès.

83. $\mathrm{MdC} /$ inv. gen. $35.90 \times 120$ $\mathrm{cm}$. La figura femenina del davant està extreta del famós quadre de Domenico Zampieri Domenichino La cacera de Diana, de la Galleria Borghese de Roma.

84. MdC / inv. gen. $53.90 \times 120$ $\mathrm{cm}$.

85. $\mathrm{MdC} /$ inv. gen. $54.90 \times 120$ $\mathrm{cm}$.

86. $\mathrm{MdC} /$ inv. gen. $4.57 \times 43 \mathrm{~cm}$. Es tracta d'una còpia cinccentista de la Sagrada Família, d'Andrea de Sarto, exposada la Galleria Nazionale d'Arte Antica de Roma.

87. $\mathrm{MdC} /$ inv. gen. $109.98 \times 90$ $\mathrm{cm}$. Escola francesa o flamenca del segle XviI?

88. $\mathrm{MdC} /$ inv. gen. $15.72 \times 87,5$ $\mathrm{cm}$. Aquesta i la següent són de la mateixa mà. Recorden l'estil dels pintors flamencs establerts a la Roma de finals del segle xviI, malgrat que també podrien tractar-se d'obres napolitanes.

89. $\mathrm{MdC} /$ inv. gen. $16.71 \times 87,5$ $\mathrm{cm}$. Podria ser un tema de Mercuri i Argos?

90. $\mathrm{MdC} /$ inv. gen. $2.27 \times 22,5$ $\mathrm{cm}$.
91. $\mathrm{MdC} /$ inv. gen. $37.48 \times 40$ $\mathrm{cm}$. No estem segurs que es tracti d'aquesta obra.

92. $\mathrm{MdC} /$ inv. gen. $3.24 \times 18 \mathrm{~cm}$ L'adscripció flamenca ens sembla vàlida.

93. $\mathrm{MdC} /$ inv. gen. $7.41 \times 28,5$ $\mathrm{cm}$. L'atribució a l'entorn de Francisco Bayeu ens sembla raonable per a una obra de molta qualitat.

94. L'anotació «cambiado» ens fa dubtar que pugui tractar-se del gravat de tema homònim conservat a la Masia, catalogat amb el registre $\mathrm{MdC} /$ inv. gen. 578.

95. MdC / inv. gen. 574. Tot i que l'anotació «cambiado» ens fa dubtar, podria ser que fos aquest gravat.

96. $\mathrm{MdC} /$ inv. gen. $10.18 \times 25 \mathrm{~cm}$.

97. Al Catálogo és un San Francisco de Paula atribuït a l'escola de Viladomat.

98. Al Catálogo ja s'indica l'adscripció a l'escola valenciana i al nom de Joanes.

99. Al Catálogo és Hércules matando un león. L'anotació «Cambiado» insinua que l'Hércules podria haver estat canviat per aquest.

100. Al Catálogo figura un San Pedro de l'escola de Viladomat que diu «cambiado».

101. Al Catálogo hi ha una Sacra Familia còpia de Correggio amb l'anotació «cambiado».

102. Al Catálogo hi ha un San Pablo amb l'anotació «cambiado».

103. Al Catálogo no s'esmenta l'atribució, que suposem que és a J. B. Flaugier.

104. Al Catálogo hi ha un País d'escola francesa amb l'anotació «cambiado».

105. Al Catálogo hi ha un País d'escola francesa.

106. Al Catálogo hi ha un Ángel de la Guarda de $13 \times 8$ polzades amb l'anotació «cambiado». Podria tractar-se del número 59 de l'inventari general de la Masia d'en Cabanyes. Ess una còpia d'un fragment de Guido Reni.

107. Al Catálogo hi ha un Jesús clavado á la Cruz amb una anotació que diu «cambiado». Podria tractar-se del cap de dona amb co- rona de llorer de la Masia (inventari general 93).

108. Al Catálogo hi ha un Retrato antiguo de muger. Es tracta d'una nova adquisició que degué fer córrer la numeració. Es conserva a la collleció Pilar Ochoa i sembla un fragment d'un quadre caravaggiesc o riberesc.

109. Al Catálogo hi ha una Virgen con el niño que diu «cambiado».

110. Al Catálogo s'adscriu a Vouet. És probable que Rius transcrivís malament la grafia i hi posés «Vernet».

111. Al Catálogo hi ha un San Juan predicando amb l'anotació «cambiado».

112. Al Catálogo hi ha una Visitacion de Nuestra Señora á Sta. Isabel on diu «cambiado».

113. Al Catálogo hi ha una Presentación on diu «cambiado».

114. Al Catálogo hi ha un San Juan adorando al niño on diu «cambiado». És la número 82 del Catálogo.

115. Al Catálogo hi ha un Cuerpo de Guardia. Ha de ser el mateix del número $79 \mathrm{~d}$ 'aquest apèndix. Podria tractar-se del número d'inventari 111 o del 41 de la Masia.

116. Al Catálogo hi ha un País. Solar antiguo de Cabanyes.

117. Es tracta del quadre ja ressenyat al número 69 del Catálogo. Número 109 de l'inventari general de la Masia.

118. $\mathrm{MdC} /$ inv. gen. $6.25 \times 20,5$ $\mathrm{cm}$. L'atribució a l'escola flamenca és encertada.

119. $\mathrm{MdC} /$ inv. gen. $9.16 \times 12 \mathrm{~cm}$. Podria tractar-se del bellíssim coure amb el tema Sant Francesc en èxtasi.

120. $\mathrm{MdC} /$ inv. gen. $61.47 \times 35$ $\mathrm{cm}$.

121. És el mateix quadre abans consignat com a Interior de la Alhambra (núm. 55 del Catálago).

122. Número 10 del Catálogo.

123. MdC / inv. gen. 110. $125 \times$ $94 \mathrm{~cm}$. Sembla una obra d'escola espanyola. Francesc CARNicer (2010), «Sabies que a la masia d'en Cabanyes hi ha una obra magnífica del barroc espanyol del segle XviI?», Quaderns de Patrimoni del Garraf, 13, p. 48 . 